Facultad de Ciencias Empresariales y Económicas

Carrera de Administración

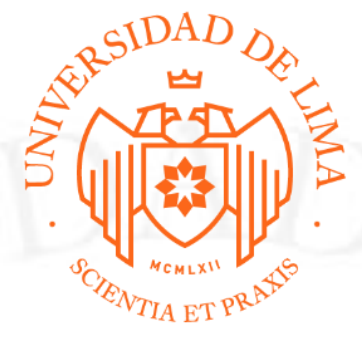

\title{
CASO DE ESTUDIO: ANÁLISIS Y \\ DIÁGNOSTICO DE UNA EMPRESA DEL SECTOR AGROINDUSTRIAL PERUANO, PROPUESTA DE UN PLAN ESTRATÉGICO
}

Trabajo de suficiencia profesional para optar el Título Profesional de Licenciado en Administración

\section{Raul Francisco Villacorta Pezo}

Código 20121385

Lima - Perú

Noviembre de 2019 
CASE STUDY: ANALYSIS AND DIAGNOSIS OF A COMPANY OF THE PERUVIAN AGROINDUSTRIAL SECTOR, PROPOSAL FOR A STRATEGIC PLAN 


\section{TABLA DE CONTENIDOS}

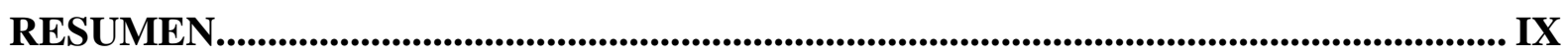

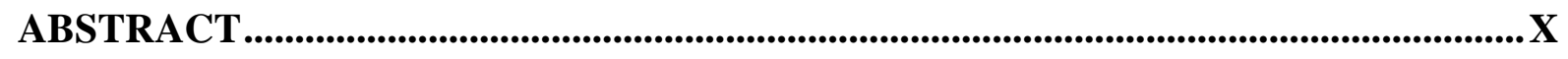

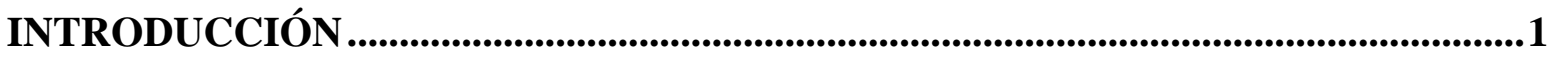

CAPÍTULO I: DIAGNÓSTICO ESTRATÉGICO .......................................................2

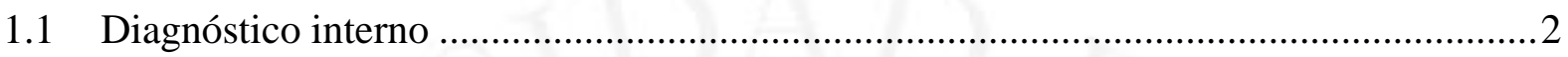

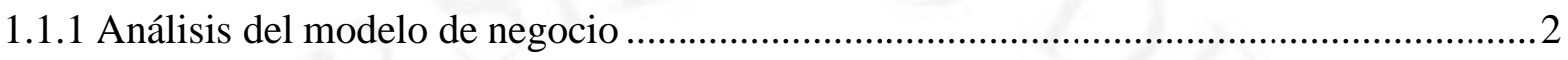

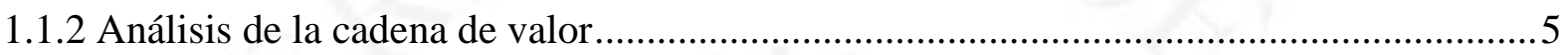

1.1.3 Definición y sustentación de las ventajas competitivas de la empresa y por Unidad

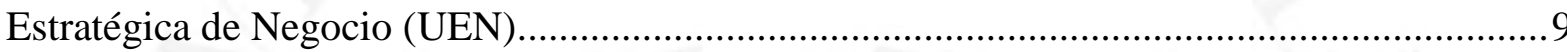

1.1.4 Determinación y sustentación de las Fortalezas y Debilidades de la empresa y por

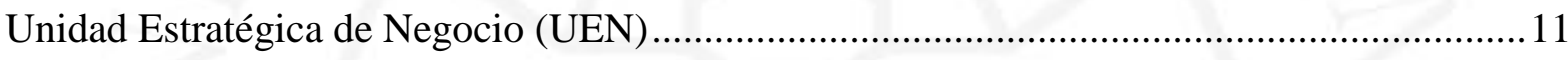

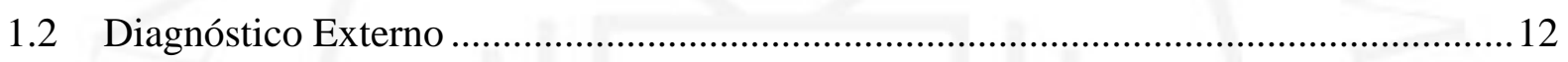

1.2.1 Análisis PEST (Sustentación de las fuerzas en base a la evolución futura de factores). 12

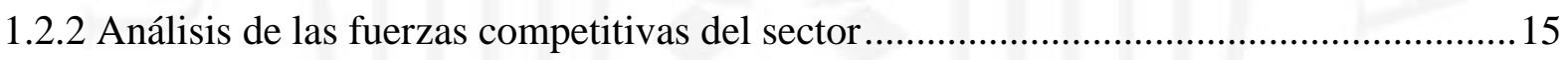

1.2.3 Determinación y sustentación de Oportunidades y Amenazas ...................................... 18

CAPÍTULO II: FORMULACIÓN DE LA ESTRATEGIA ...............................................20

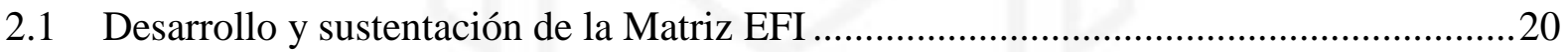

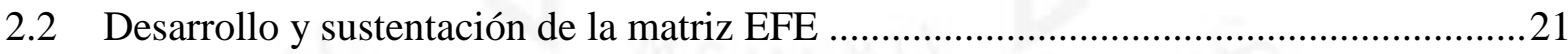

2.3 Matriz de la Estrategias Genéricas (Sustento) ............................................................22

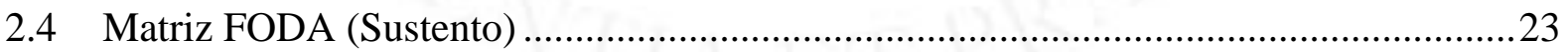

2.5 Definición y sustentación de la Visión, Misión y Políticas ...........................................25

2.6 Definición de los Objetivos Estratégicos de la empresa .............................................26

2.7 Redefinición de las Unidades Estratégicas de Negocio (UEN) o creación de nuevas UEN

2.8 Propuesta y sustentación de estrategias en el ambiente Global, Corporativas de Negocios y Funcionales. 
3.1. Evaluación del rediseño o no rediseño de la estructura organizacional de la empresa (Sustento)

3.2 Propuesta de cambios para mejorar la implementación de estrategias en la empresa....33

CAPÍTULO IV: CONTROL ESTRATÉGICO. .35

4.1. Diseño de un Mapa Estratégico de Control para la empresa. .35

4.2 Desarrollo de un Cuadro de Mando Integral con un mínimo de diez índices de gestión

CONCLUSIONES 37

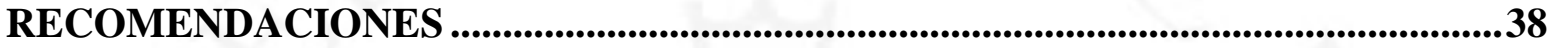

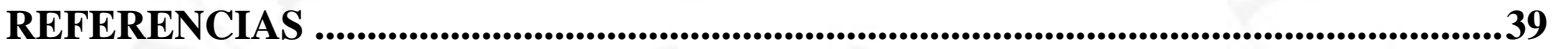

BIBLIOGRAFÍA .............................................................................................................42

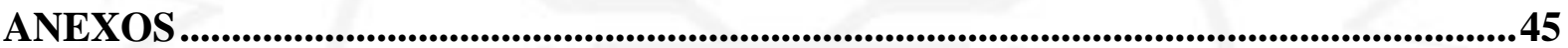




\section{ÍNDICE DE TABLAS}

Tabla 1.1 Matriz Lienzo de Alexander Osterwalder...........................................................5

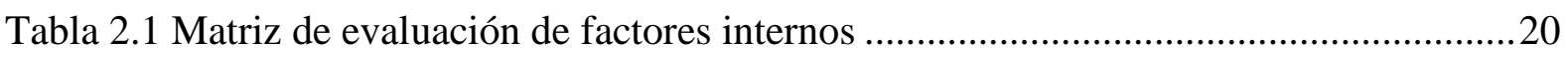

Tabla 2.2 Matriz de evaluación de factores externos.........................................................21

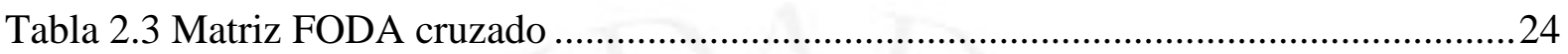

Tabla 4.1 Cuadro de Mando Integral empresa Camposol..................................................... 36 


\section{ÍNDICE DE FIGURAS}

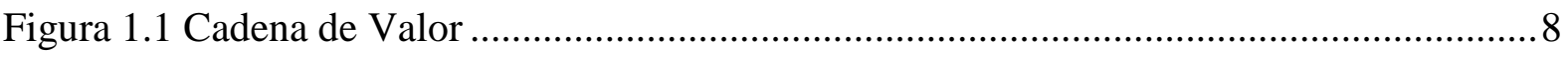

Figura 1.2 Formación de la Ventaja Competitiva............................................................

Figura 2.1 Matriz de las Estrategias Genéricas de Michael Porter ......................................22

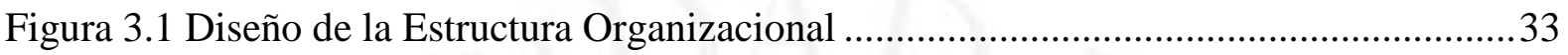

Figura 4.1 Mapa Estratégico de empresa Camposol.............................................................. 35 


\section{ÍNDICE DE ANEXOS}

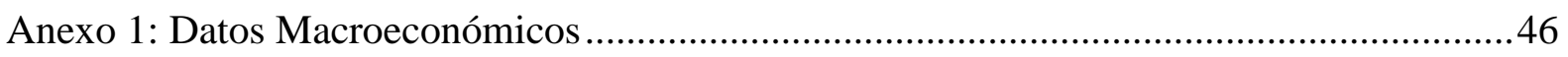

Anexo 2:Proyección de Tipo de Cambio ......................................................................... 47

Anexo 3: Competidores de Camposol en Perú ............................................................... 48 


\section{RESUMEN}

El presente trabajo consta de cuatro capítulos que permiten realiza un análisis exhaustivo de situación actual de la empresa Camposol.

El primer capítulo está conformado por un análisis interno y externo. El análisis interno permitirá conocer cuáles son las fortalezas y debilidades dentro de la empresa, con que ventaja competitiva cuenta, cuál es el modelo de negocio concreto que ofrece e identificar cuáles son las unidades estratégicas que tiene. Respecto al análisis externo, ha permitido encontrar oportunidades y amenazas que se encuentran en el entorno externo de empresas agroindustriales.

El segundo capítulo, da a conocer que estrategias se han planteado para mejorar el rendimiento de toda la estructura de la empresa Camposol, y de ser necesario plantear estrategias para corregir aquellas actividades que no están generando el valor deseado. Este segmento constituye la segunda etapa de la administración estratégica, etapa en la cual se marca el camino a seguir.

El tercer capítulo constituye la tercera etapa de la administración estratégica; es decir, la implementación de lo que se planteó como estrategia en el capítulo anterior. En esta etapa se desarrollan y aplican las estrategias propuestas para la empresa Camposol, así como correcciones en la estructura, de igual manera se hace énfasis en la capacidad de comunicar asertiva y adecuadamente las acciones a realizar dentro de la empresa.

El cuarto capítulo del presente trabajo, implica el control que se realiza a los capítulos anteriormente explicados; el control en Camposol es llevado a cabo a través de un mapa estratégico de control y un cuadro de mando lleno de indicadores clave de gestión. El proceso de control debe servir para realizar retroalimentación en todos los procesos de la empresa.

Palabra Clave: Camposol, Análisis Interno y Externo, Estrategias, Implementación, Control. 


\begin{abstract}
This work consists of four chapters that allow an exhaustive analysis of the current situation of the Camposol Company.

The first chapter is made up of an internal and external analysis. The internal analysis will allow to know what are the strengths and weaknesses within the company, with what competitive advantage it has, what is the specific business model that it offers and indentify which are the strategic units it has.

The second chapter, reveals that strategies have been proposed to improve the performance of the entire structure of the Camposol company, and if necessary to propose strategies to correct those activities that are not generating the desired value. This segment constitutes the second stage of strategic management, a stage in which the way forward is marked.

The third chapter constitutes the third stage of strategic management; that is, the implementation of what was raised as a strategy in the previous chapter. At this stage the strategies proposed for the Camposol company are developed and applied, as well as corrections in the structure, in the same way emphasis is placed on the ability to assertively and adequately communicate the actions to be carried out within the company.

The fourth chapter of this paper implies the control that is carried out to the chapters explained above; Control in Camposol is carried out through a strategic control map and a dashboard full of key management indicators. The control process should serve to provide feedback on all the processes of the company.
\end{abstract}

Keywords: Camposol, Strengths, Performance, Implemetation, Control. 


\section{INTRODUCCIÓN}

El presente análisis tiene como objetivo brindar un estudio de tipo académico profesional, donde se explican conceptos administrativos y se proponen nuevas ideas que la empresa en análisis puede realizar para seguir generando valor.

La empresa Camposol constituye un caso de análisis único, ya que ha pasado por diferentes etapas desde sus inicios, hasta la actualidad, dado que ha operado en épocas de crisis económica y en épocas de estabilidad. Actualmente, la empresa es el mayor productor de Aguacates en el mundo y se perfila también a ser uno de los principales abastecedores de Arándanos a nivel internacional. La empresa cuenta con la habilidad de haber diversificado correctamente sus recursos, puesto que también cuenta con una unidad de negocio de Mariscos tales como camarones, calamares y vieiras. De igual manera cuenta con su propia comercializadora para sus productos y de esta manera atender mejor a sus clientes internacionales.

Indicar que el presente trabajo va a permitir al lector entender como la empresa Camposol monitorea las variables externas del macro entorno a través de un análisis PEST, entender que actividades son clave en la empresa a través de la Cadena de Valor, conocer que estrategias genéricas, globales, corporativas y funcionales desarrolla la organización en cuestión de análisis, entender en donde radica su ventaja competitiva, comprender como es la rivalidad en la industria agroexportadora, estimar si las estrategias propuestas en la matriz FODA son las más adecuadas, visualizar el mapa estratégico y su respectivo cuadro de mando con indicadores de gestión, conocer como es la estructura organizacional de Camposol y la propuesta de mejora en este aspecto, entender cuál es el propósito o razón de ser de la empresa y hacia dónde quiere llegar a futuro, entre otros conceptos importantes que se desarrollan en este trabajo.

El trabajo realizado representó para mí una gran oportunidad de haber conocido a fondo la industria agroexportadora en el país, permitiéndome aportar estrategias que he tenido el agrado de haber aprendido en el ámbito académico y laboral, que sin duda me ayudarán como futuro administrador, y es por ello que este trabajo contiene propuestas de mejora hacia la empresa Camposol. 


\section{CAPÍTULO I: DIAGNÓSTICO ESTRATÉGICO}

\subsection{Diagnóstico interno}

\subsubsection{Análisis del modelo de negocio}

Para iniciar el análisis del presente trabajo, es necesario poder desarrollar y explicar el modelo de negocio bajo el cual la empresa Camposol realiza sus operaciones. En ese sentido, es necesario establecer qué es un Modelo de Negocio, es por ello que Osterwalder ( 2012) afirma: “ Un modelo de negocio describe las bases sobre las que una empresa crea, proporciona y capta valor”(p.14).

A continuación se detalla esta herramienta aplicada a la empresa Camposol:

1. ¿Qué ofrece la empresa?

\section{Propuesta de Valor}

La empresa Camposol se caracteriza al ofrecer una propuesta de valor que otorga productos de calidad, producción a gran escala, capacidad de establecer precios fijos y entregas a tiempo. Todas estas características que se han señalado, es debido a que es productor y vendedor de sus propios productos.

Asimismo, la empresa genera relaciones de largo plazo con sus clientes a través de las características señaladas, debido a que los minoristas prefieren realizar negocios con la empresa Camposol, porque es más fácil y rápido, y de esta manera la estrategia de marca ayuda a desarrollar relaciones duraderas.

La empresa cuenta con los siguientes productos y que son los más importantes dentro de su cartera: Aguacates, Arándanos, Espárragos. De igual manera, cuenta con un negocio de productos de mar.

2. ¿A quién ofrece la empresa?

\section{Segmentos del Mercado}

La empresa Camposol a lo largo del tiempo ha tenido un enfoque en los clientes minoristas; es decir, aquellos que llevan el producto hacia el consumidor final. "La empresa Camposol, cuenta en Estados Unidos con los siguientes clientes minoristas: Costco, Kroger, Publix, Walmart y otras cadenas. En Europa los principales clientes son 
Tesco y Marks y Spencer" (Bell y Kindred, 2016, p.10). Asimismo, es necesario mencionar que actualmente también se cuenta con clientes minoristas en América Latina y Asia, solo que representan volúmenes menores para la organización.

\section{Canales}

Anteriormente la empresa Camposol empezó utilizando un esquema de Canales a través de Distribuidores; es decir, ellos solo se encargaban de producir sus productos para posteriormente delegar el proceso de venta o comercialización a un tercero. Actualmente, la empresa Camposol, cuenta con una comercializadora para la venta y comercialización de sus productos. Según Bell y Kindred (2016): “En el año 2015, aproximadamente el $60 \%$ del volumen del total de la producción de la empresa, fue comercializado por medio de su unidad comercial" (p.10).

\section{Relaciones con los clientes}

En la empresa Camposol, se ha podido identificar que al inicio de sus operaciones, la empresa no contaba con una marca o estrategia de marca que justamente le ayudará a generar relaciones de valor con los clientes. Una vez que la empresa logró consolidar su comercializadora y su estrategia comercial, por ello Bell y Kindred( 2016) afirman:” La organización Camposol en el año 2016, empezó a utilizar dos marcas: "Camposol” para productos de alta calidad y "Sol Produce" para productos premium"(p.12). De esta manera logran diferenciarse y generar relaciones duraderas.

3. ¿Cómo ofrece la empresa?

\section{Asociaciones Clave}

La empresa Camposol puso en desarrollo una estrategia para construir relaciones con aquellos minoristas que, según Bell \& Kindred (2016) afirman: "Consideran que el modelo de integración vertical de Camposol era una ventaja competitiva" (p.13). De acuerdo a esto, la empresa logró asociaciones con los principales minoristas en Estados Unidos (Walmart, Kroger, Costco, etc) y Europa ( Tesco y Mak y Spencer).

De igual manera, estas asociaciones permiten a la empresa Camposol utilizar las plantas de maduración con las que cuentan los minoristas, allá en destino.

\section{Actividades Clave}

En la empresa Camposol, se ha identificado las siguientes actividades clave:

1.- Producción Agrícola: Actualmente, la empresa cuenta con más de 5,000 hectáreas de diversas frutas y verduras como espárragos, aguacates, arándanos, mangos, etc. 
2.- Empaque: Actividades que se realizan para asegurar que el producto pueda trasladarse desde Perú a destino, sin riesgo de sufrir algún desperfecto.

3.- Comercialización: La creación de la comercializadora ayuda a otorgar rápida rotación a los productos, así como a desarrollar relaciones con los clientes.

\section{Recursos Clave}

En la empresa Camposol se han identificado los siguientes recursos considerados clave:

1.- Campos de cultivo de frutas y verduras: Desde allí se obtienen los productos.

2.- Mano de Obra: En los procesos más importantes que lleva a cabo la empresa (recolección, producción, empaquetado y distribución) son llevado a cabo por personas.

3.- Infraestructura de Planta: La empresa Camposol maneja grandes cantidades de volúmenes y necesita tener la capacidad para poder procesarlos.

La herramienta de Alexander Osterwalder cuenta con dos elementos adicionales que se utilizan con los 3 grupos de forma indistinta. A continuación se detalla y desarrolla estos dos elementos para el caso específico de la empresa Camposol:

\section{Estructura de Costos}

La empresa Camposol, cuenta con una estructura de costos bajo, porque como producen grandes cantidades de volúmenes, han podido desarrollar economías de escalas y de aprendizaje. Asimismo, otra de las razones por la que cuenta con una estructura de bajo costos, es debido a que la empresa, no cuenta con Plantas de Maduración, sino que utiliza las de sus clientes (Bell y Kindred, 2016).

\section{Fuentes de Ingresos}

La fuente de ingresos de la empresa proviene de la venta a los supermercados en Estados Unidos, Europa y Asia, principalmente. Asimismo, la organización cuenta con ingresos constantes ya que ha podido crear relaciones de largo plazo con sus clientes. 
Tabla 1.1

Matriz Lienzo de Alexander Osterwalder

\begin{tabular}{|c|c|c|c|c|}
\hline \multirow[t]{2}{*}{$\begin{array}{l}\text { Clientes minoritas } \\
\text { internacionales } \\
\text { que consideran } \\
\text { que el modelo de } \\
\text { integración } \\
\text { vertical es una } \\
\text { ventaja } \\
\text { competitiva }\end{array}$} & $\begin{array}{c}\text { Actividades clave } \\
\text { Producción Agrícola, } \\
\text { empaque y } \\
\text { comercialización }\end{array}$ & $\begin{array}{l}\text { Propuesta de valor } \\
\\
\text { Productos de alta } \\
\text { calidad, producción a } \\
\text { gran escala, } \\
\text { capacidad de } \\
\text { establecer precios } \\
\text { fijos y entregas a } \\
\text { tiempo. }\end{array}$ & $\begin{array}{c}\text { Relaciones con los } \\
\text { clientes } \\
\text { Empresa Camposol } \\
\text { desarrolla relaciones } \\
\text { a través de su } \\
\text { estrategia de marca, } \\
\text { porque } \\
\text { le permite } \\
\text { diferenciarse de sus } \\
\text { competidores }\end{array}$ & \multirow[t]{2}{*}{$\begin{array}{l}\text { Enfoque en los } \\
\text { clientes } \\
\text { minoristas } \\
\text { internacionales; } \\
\text { es decir, } \\
\text { súpermecados } \\
\text { de renombre } \\
\text { global. }\end{array}$} \\
\hline & $\begin{array}{c}\text { Recursos Clave } \\
\text { Campos de cultivos } \\
\text { de frutas y verduras, } \\
\text { mano de obra e } \\
\text { infraestructura de } \\
\text { planta }\end{array}$ & & \begin{tabular}{l}
\multicolumn{1}{c|}{ Canales } \\
Anteriormente \\
utilizaba \\
distribuidores. \\
Actualmente cuenta \\
con comercializadora \\
propia para sus \\
productos.
\end{tabular} & \\
\hline \multicolumn{3}{|c|}{ Estructura de costos } & \multicolumn{2}{|c|}{$\begin{array}{l}\text { Fuentes de ingreso } \\
\text { Proviene de la venta a los clientes } \\
\text { minoristas, estos ingresos son constantes } \\
\text { porque ya desarrollaron relaciones a largo } \\
\text { plazo. }\end{array}$} \\
\hline
\end{tabular}

Fuente: Osterwalder ( 2012)

Elaboración propia.

\subsubsection{Análisis de la cadena de valor}

La cadena de valor, según David (2013) afirma:" Se refiere al proceso por el cual una empresa determina el costo asociado con las actividades de la organización, desde la compra de la materia prima hasta la fabricación del producto y su comercialización" (p.119).

Para el presente análisis interno se ha seleccionado La Cadena de Valor como herramienta que permite la identificación de las actividades que son consideradas clave o también llamadas actividades primarias, así como las actividades de Apoyo. A continuación se desarrollará la cadena de valor de la empresa Camposol:

\section{Actividades Primarias}

- Logística Interna: Se considera que la actividad de logística interna es actividad primaria, porque es la primera actividad en el eslabón que empieza 
con la obtención de las diversas semillas que se necesita para plantar las frutas y verduras. Posteriormente también se realiza la preparación y cuidado de la tierra.

- Producción: Esta actividad es primaria porque produce grandes volúmenes de diversas frutas y verduras, logrando economías de escala como empresa líder. De igual manera, la empresa toma cuidado con la calidad del fruto que se está procesando, procurando que el producto sea el más óptimo en sabor y tamaño.

- Logística de Salida: Actividad primaria, debido a que la empresa Camposol tiene una gran gestión en programación y cronograma de pedidos, y de igual manera de almacenamiento, porque despachan el pedido de sus clientes en el menor tiempo posible, en la calidad deseada y en la cantidad requerida.

- Marketing y Ventas: Actividad realizada a través de su propia comercializadora pudiendo la empresa Camposol realizar una integración hacia adelante; es decir, volverse distribuidor también. La venta se realiza antes del envío y es en el momento en que se firman los contratos con los minoristas.

- Distribución: Es la misma empresa Camposol que se encarga de realizar la distribución desde el punto de origen hacia destino, y no a través de un tercero, permitiendo que ellos mismos sean los que aseguran sus tiempos de entrega (Bell y Kindred, 2016).

- Servicio Post Venta: La empresa Camposol, constantemente está en la búsqueda de desarrollar relaciones de largo plazo con sus clientes, ofreciendo seguimiento al proceso de maduración que se da en las instalaciones de maduración que poseen los clientes o reposición inmediata, en caso los productos hayan salido defectuosos.

\section{Actividades de Soporte}

- Mejoramiento de Procesos: La empresa Camposol busca constantemente mejorar los procesos de cuidado de campos, cultivos, cosecha, traslado de frutas, procesamiento, empaque, etc., que le permita seguir siendo líder de la industria. 
- Administración de los Recursos Humanos: Actividad que se encarga de reclutar y capacitar a los colaboradores que laboran en la empresa Camposol, con el objetivo de fidelizarlos.

- Administración de los Servicios Legales: En la empresa Camposol, esta área se vuelve necesario para revisar los contratos con los minoristas, porque hay muchos compromisos de venta a nivel internacional.

- Administración Financiera: Área encargada de gestionar los activos, pasivos y patrimonio de la empresa.

Se concluye que la organización tiene una ventaja competitiva de Eficiencia Superior, porque a pesar de manejar grandes volúmenes, tiene la capacidad para gestionarlos de manera sobresaliente, pudiendo atender a sus clientes en grandes cantidades, precios fijos y menor tiempo. Asimismo, Camposol cuenta con Calidad Superior, porque dado que la mayor parte de sus productos vienen de una sola área, las frutas y verduras cuentan con una calidad consistente en cuánto a sabor y tamaño. 
Figura 1.1

Cadena de Valor

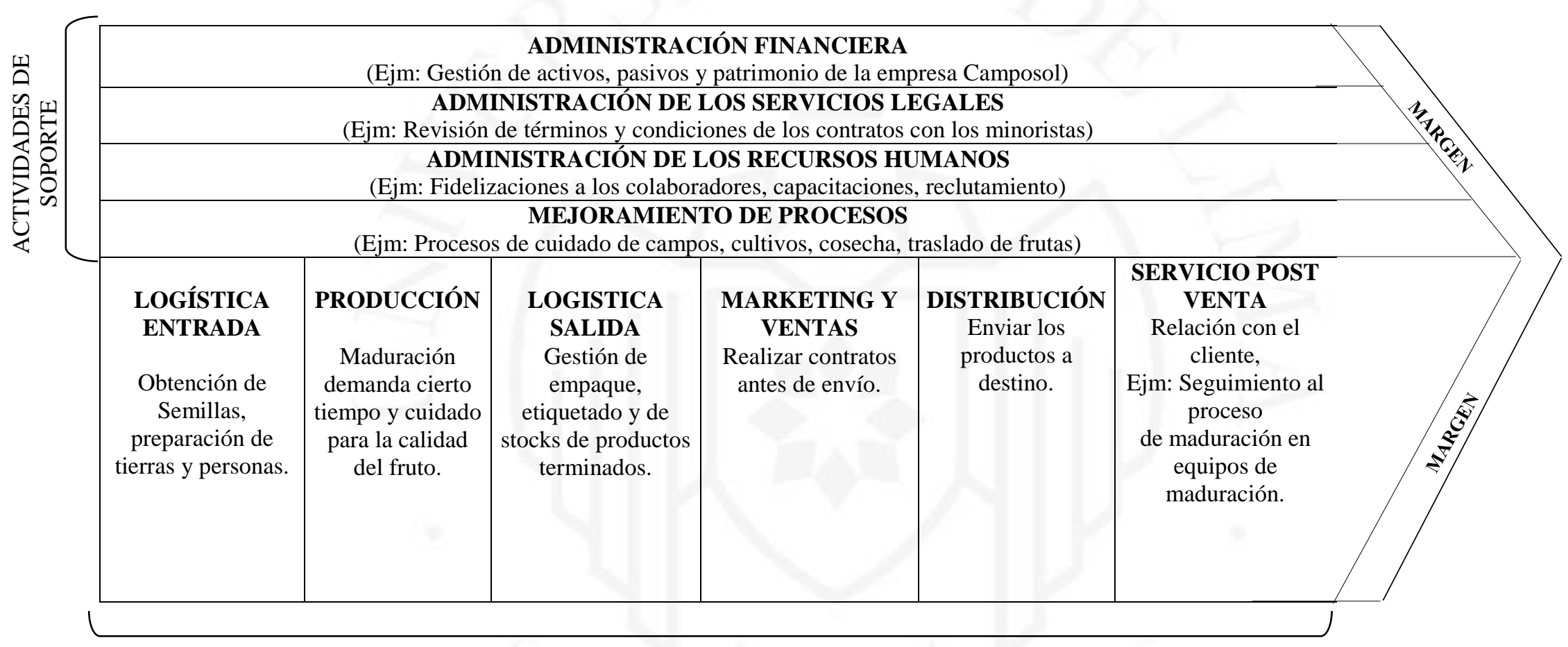

Fuente: Porter(2010)

ACTIVIDADES PRIMARIAS

Elaboración propia 


\subsubsection{Definición y sustentación de las ventajas competitivas de la empresa y por Unidad Estratégica de Negocio (UEN)}

Hill, Jones, \& Schilling(2015) afirman: “Una compañía desarrolla y sostiene su ventaja competitiva con la ayuda de cuatro factores: eficiencia, calidad, innovación y respuesta al cliente" (p.93). Con los factores que mencionan estos autores, se puede lograr que la ventaja competitiva sea difícil de copiar y sostenible en el tiempo. De igual manera, desde otro punto de vista, Ghemawat (2007) sostiene:” Una firma ha creado ventaja competitiva sobre sus rivales cuando ha establecido una distancia más amplia que sus competidores entre la disposición a pagar y los costos" (p.62).

El análisis de la Ventaja competitiva se podrá realizar utilizando la herramienta de "los cuatro bloques de la Ventaja Competitiva", elaborada por Michael Porter en su libro "Ventaja Competitiva" (Porter, 2010).

Figura 1.2

Formación de la Ventaja Competitiva

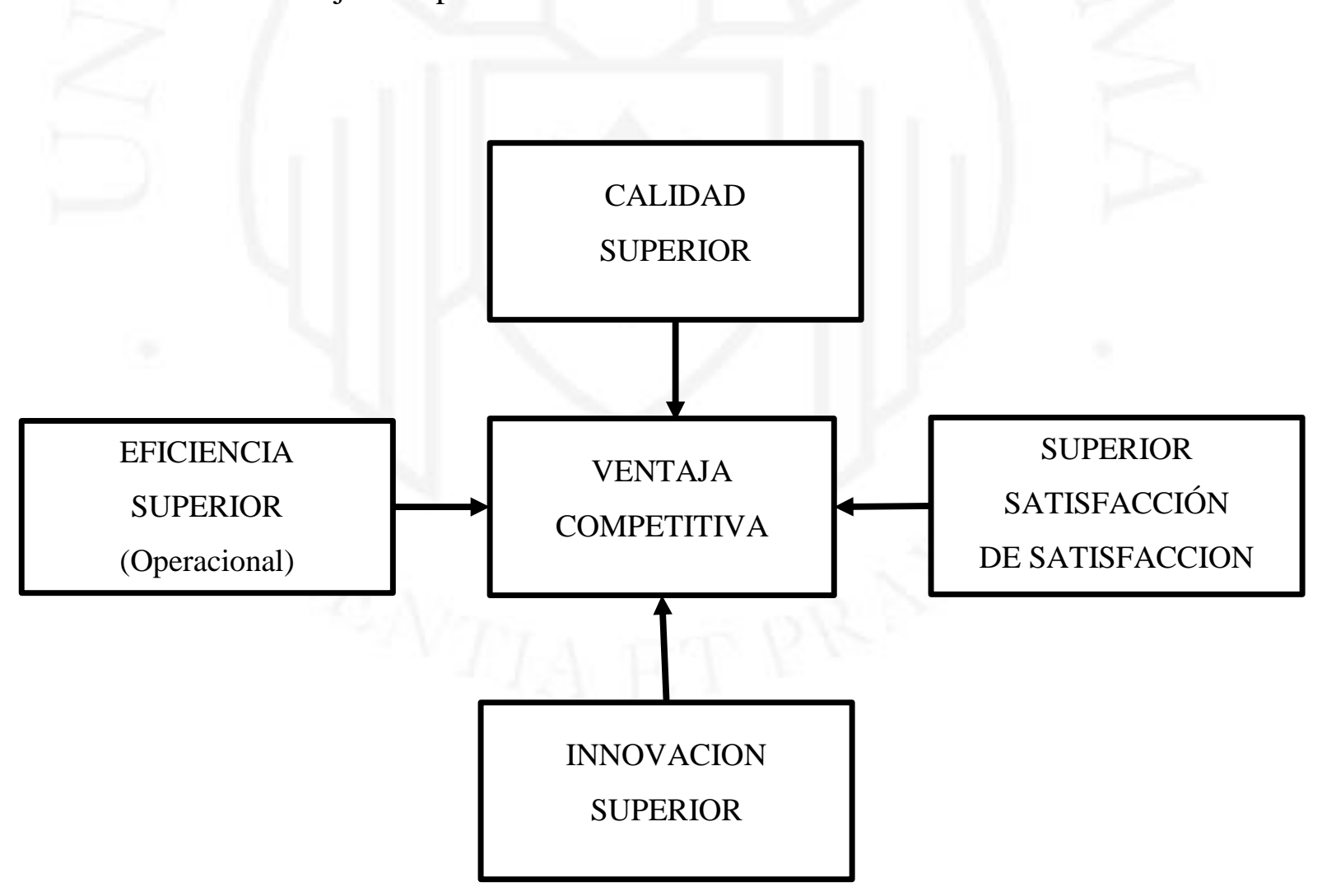

Fuente: Porter, M. (2010).

Elaboración propia. 
Después del análisis realizado se ha identificado que la empresa Camposol, ha desarrollado las siguientes ventajas competitivas para todas sus Unidades Estratégicas de Negocio (UEN):

\section{Calidad Superior}

La empresa Camposol cuenta con Calidad Superior, porque gran parte de los productos que ofrece, vienen de un área determinada, generando que el sabor y textura de las frutas que produce, sean consistentes y homogéneas, ya que sus competidores de distribución deben obtener las frutas de diferentes productores, y esto hace que la calidad no sea la mejor (Bell y Kindred, 2016).

Asimismo, la empresa Camposol ejerce un fuerte control de calidad desde el inicio de la obtención de las frutas, por ejemplo con los arándanos, el recojo de la cosecha se hace a través de personas y no máquinas, permitiendo que la fruta no se maltrate o sufra algún desperfecto, ya que recoger por medio de máquinas, genera mucha pérdida. (Bell y Kindred, 2016)

\section{Eficiencia Superior}

Se sostiene que la empresa Camposol cuenta con esta ventaja competitiva porque ha logrado desarrollar gran gestión de su know how en manejo de campos de cultivo, a pesar de que maneja numerosas hectáreas de campo. De igual manera, a raíz de esta ventaja, los colaboradores se han especializado en la labor con frutas.

También se argumenta que la empresa Camposol, logra esta ventaja por medio de su gran gestión de stocks de productos terminados, dado que la empresa siempre cuenta con el stock adecuado para cada uno de sus clientes, generando que no haya mermas ni demoras en la atención a los minoristas.

\section{Superior Capacidad de Satisfacción al Cliente}

Entonces, dado que Camposol cuenta con las dos ventajas competitivas antes explicadas, se argumenta que la empresa comienza a fortalecer o desarrollar la ventaja competitiva de superior satisfacción al cliente, porque al ofrecer un producto de calidad superior y tener una eficiencia superior en las operaciones, permite que el cliente obtenga un producto superior, en grandes cantidades y en el menor tiempo posible, generando que el cliente esté a gusto. De igual manera, se sostiene que la empresa está desarrollando superior satisfacción con el cliente, porque constantemente está buscando desarrollar 
relaciones a largo plazo, y una de las acciones para lograr esto es que una vez que se entrega la fruta y estás se llevan a las instalaciones de maduración que posee el cliente minorista, la organización se encarga de verificar que el proceso de maduración final de la fruta vaya de acuerdo a la calidad que se suele utilizar.

\subsubsection{Determinación y sustentación de las Fortalezas y Debilidades de la empresa y por Unidad Estratégica de Negocio (UEN)}

Con el análisis realizado en la cadena valor de la empresa Camposol, se ha identificado las siguientes fortalezas y debilidades que hay en la principal UEN, que es la de frutas y verduras:

\section{Fortalezas}

- Kow How en gestión de campo: La empresa Camposol tiene el Know How de cómo gestionar los campos de cultivos para que alcancen un rendimiento alto en zonas desérticas.

- Desarrollo de economías de escala: A nivel de empresa líder en su industria.

- Gran gestión en programación, cronograma de pedidos y almacenamiento: Logra despachar el pedido de sus clientes en el menor tiempo posible, en la calidad deseada y en la cantidad requerida.

- Gran control de toda la cadena: Al haber realizado una integración hacia adelante, convirtiéndose también en un distribuidor de sus mismos productos.

- Desarrollo de relaciones a largo plazo: La empresa constantemente está buscando desarrollar relaciones de largo plazo con sus clientes.

\section{Debilidades}

- Centralización de Campos de Cultivo: La mayor parte de sus campos de cultivo están localizados en el noroeste de Perú, por tanto cualquier imprevisto impedirá que cumpla con todos sus pedidos. (Bell y Kindred, 2016)

- Mano de Obra Insuficiente: Se cuenta con mano de obra escasa en período de mayor producción. (Bell y Kindred, 2016)

- Dependencia de Clientes: La empresa Camposol no puede terminar el proceso de maduración de las frutas y verduras, ya que no cuenta con las instalaciones de maduración. (Bell y Kindred, 2016) 
- Riesgo de Marca: La marca es el mismo nombre de la compañía, cualquier desperfecto, el nombre y prestigio de toda la organización se puede ver severamente perjudicado.

- Dificultad en Servicio Post Venta: Servicio con un poco de limitaciones, ya que se realiza en rubro de frutas.

\subsection{Diagnóstico Externo}

\subsubsection{Análisis PEST (Sustentación de las fuerzas en base a la evolución futura de factores)}

El análisis a continuación permite estudiar el Macro Entorno, que es aquel entorno que la empresa no puede tener control sobre él, debido a que son variables externas, y según Wheelen y Hunger (2013) afirman: “El entorno externo esta integrado por variables que se encuentran fuera de la organización( Oportunidades y Amenazas) y que no están comumente bajo el control a corto plaza de la alta gerencia"(p.17). Es decir que afectan a todas las empresas de la industria. Por otro lado, permite estudiar cómo están evolucionando estos factores y si representan una amenaza o una oportunidad para el rendimiento y desarrollo de la organización.

Para estudiar estas variables externas que la empresa no tiene control, se agrupan en los siguientes grupos: Político-Legal, Económico, Socio Cultural, Tecnológico y Ecológico. A continuación se desarrolla el análisis para la empresa Camposol:

\section{Político-Legal}

- Leyes laborales del sector. El régimen agrario se basa en la ley 27360, actualmente esta ley se ha extendido, generando una oportunidad, ya que esta norma establece que los contratos con los colaboradores sean de empresa mype. (Gobierno del Perú, 2019).

- Incertidumbre política, debido a constante enfrentamiento entre poder legislativo y poder ejecutivo, esto representa una amenaza porque de no haber estabilidad en el plano político, los inversiones se paralizarán. (El Comercio, 2019). 
- La firma del acuerdo de TLC con Estados Unidos cumple 10 años, y esto representa una oportunidad, ya que el impacto ha sido positivo y se espera que lo siga siendo. (Castillo, 2019).

- Optimización del TLC con China, esto representa una oportunidad porque otorga facilidades para los exportadores y genera nuevas oportunidades, ya que actualmente China es el principal socio comercial de Perú. (Gestión, 2019)

\section{Económico}

- Actualmente las estimaciones de crecimiento económico de Perú para el 2019 se redujeron debido a una caída en la inversión interna y en los precios de materias primas, representando una amenaza, ya que a mayor crecimiento del PBI, mayor crecimiento de las exportaciones. (RPP, 2019)

- A Junio del 2019 la Inflación se mantuvo en 2\%, esto representa una oportunidad porque quiere decir que una tasa de inflación baja, se mantiene en el rango meta entre $2.4 \%$ a $2.5 \%$. (Banco Central de Reserva del Perú, 2019).( Ver Anexo 1 )

- Las exportaciones de bienes y servicios de Perú se redujeron a 2.6\% para el mes de Junio del 2019, representando una amenaza, ya que lo ideal es que las exportaciones aumenten. (Banco Central de Reserva del Perú, 2019)

- Las proyecciones del Tipo de Cambio sostienen que estará estable para el próximo año en un rango de S/. 3.32 a S/. 3.34, generando una oportunidad para el sector exportador. (Gestión, 2019).( Ver Anexo 2 )

- Las exportaciones peruanas de frutas crecieron en un $9.5 \%$ en el primer trimestre del 2019, generando una oportunidad a las empresas agroindustriales. (América Economía, 2019)

\section{Socio Cultural}

- Mayor conciencia de los consumidores de Estados Unidos respecto a los beneficios para la salud de los aguacates, representa una oportunidad porque genera que mayor cantidad de personas busque el producto. (Bell y Kindred, 2016) 
- Mayor interés de los consumidores por alimentos frescos y saludables, esto es una oportunidad porque se crea una tendencia hacia productos sanos. (Bell y Kindred, 2016)

- Se incrementa la aceptación de productos orgánicos entre los consumidores, representa una oportunidad porque permite generar una nueva categoría de productos. (Bell y Kindred, 2016)

- Productos como frutas y verduras, son alimentos, por lo que están asociado con la vida, cualquier desperfecto en el producto el consumidor se alejará definitivamente, esta situación genera una amenaza para todo el sector. (Bell y Kindred, 2016)

- La valoración por empresas ambientalmente y socialmente responsables se eleva dado que hay una tendencia a cuidar de las personas y el medio ambiente, generando una oportunidad porque permite capitalizar las buenas prácticas. (Bell y Kindred, 2016)

\section{Tecnológico}

- Nuevas tecnologías para plantas de empaque que permiten calibrar la fruta por tamaño, generando una oportunidad ya que también se puede hacer la oferta por tamaño. (Bell y Kindred, 2016)

- Actualmente, existe técnicas de riego por goteo impulsado por la gravedad, que permite el ahorro en el uso del agua, convirtiéndose en una oportunidad, porque genera que el proceso de riego sea más eficiente. (Bell y Kindred, 2016)

- Avances en el campo de Investigación y Desarrollo enfocados en el control de plagas naturales, la cría y otras áreas, significando una oportunidad porque permite tener un mayor conocimiento de las plagas. (Bell y Kindred, 2016)

\section{Ecológico}

- En el Noroeste de Perú hay condiciones ideales para la Agricultura: temperaturas estables todo el año, viento mínimo y lluvias previsibles, es una oportunidad porque al ser las lluvias previsibles y casi nulas, los campos no corren riesgo de inundarse. (Bell y Kindred, 2016)

- Corriente de Humboldt crea un buen ecosistema en el Noroeste de Perú, porque permite producir frutas que generalmente encuentras en los 
hemisferios norte o sur y también posibilita cosechar durante muchos meses e incluso en algunas oportunidades todo el año, oportunidad única que brinda esa zona del país. (Bell y Kindred, 2016)

- Ocurrencia del fenómeno climatológico El Niño en el año 2014 y 2017, representa una amenaza porque la magnitud de este fenómeno no es posible cuantificar del todo. (Bell y Kindred, 2016)

\subsubsection{Análisis de las fuerzas competitivas del sector}

El presente instrumento es otra de las herramientas para realizar el análisis externo; sin embargo, este se enfoca en estudiar al micro entorno; es decir, sector o industria en donde opera la empresa y como es el grado de competencia o rivalidad que hay entre todos los competidores. Según Betancourt G.(2014) afirma: "Este marco de 5 fuerzas provee una forma sistemática de pensar como las fuerzas competitivas trabajan en las diferentes industrias y segmentos" (p.67).

Asimismo, permite identificar oportunidades y amenazas que genera la rivalidad dentro del sector industrial. A continuación se presenta el análisis realizado para la industria agroindustrial:

\section{Amenaza de Nuevos Ingresos}

1. Economías de Escala: La industria en cuestión de análisis, tiene como característica que todas las empresas que la conforman logran desarrollar economías de escala porque deben producir grandes cantidades haciendo disminuir el costo unitario, y también lograr estandarizar procesos para poder producir en un menor tiempo posible. Entonces, de acuerdo a lo que se explicó, este factor otorga una barrera de entrada alta.

2. Requisito de Capital: En la industria agroindustrial, es necesario tener mucho capital para poder operar ya que se debe de tener campos de cultivo, plantas de producción y empaque, cámaras de refrigeración, maquinaria, mano de obra grande, etc. Por lo que se ha explicado, se puede afirmar que los requisitos de capital son una barrera de entrada alta para nuevos competidores.

Se concluye que no hay una amenaza real de nuevos competidores, ya que existen barreras altas de entrada a la industria. 


\section{Amenaza de Productos Sustitutos}

La manera de analizar este factor es sosteniendo que en esta industria se ofrecen productos base; es decir, productos únicos tales como las frutas, en el cual los clientes necesitan el producto y ellos consideran que no hay sustitutos para los productos que se ofrecen en la industria.

Entonces, dado que la industria ofrece alimentos con beneficios únicos para la salud, y así lo entienden los clientes minoristas, se llega a la conclusión de que es baja la amenaza de productos sustitutos.

\section{Poder de Negociación de Proveedores}

Se argumenta que las empresas en esta industria son sus propios proveedores en sí, porque cada empresa es la que tiene el control de su cadena de abastecimiento de insumos, ya que cuenta con sus propios campos de cultivo, realiza el cuidado de las frutas y verduras, se encarga de la recolección, procesamiento y empaquetado del producto, siendo esto las actividades más importantes que pudiera realizar un proveedor en esta industria.

Por lo tanto, se concluye que el poder de negociación de los proveedores en la industria es baja, ya que las empresas mismas son sus propios proveedores en los insumos y actividades más importantes que necesitan para operar, logrando una integración hacia atrás.

\section{Poder de Negociación de los Clientes}

En esta industria los productos; es decir, las frutas, necesitan un proceso de maduración final que es logrado a través de las plantas de maduración, pero estas son de propiedad de los cliente (Bell y Kindred, 2016). De esta mañanera, genera que los clientes tengan un gran poder de negociación, ya que se depende de ellos para que el producto llegue a su punto óptimo; sin embargo, las empresas de mayor prestigio han logrado desarrollar marcas de calidad que son reconocidas por los consumidores finales, con lo cual los minoristas no van a querer cambiar a la empresa porque está ya cuenta con un posicionamiento solido dentro del mercado de frutas.

Entonces, se concluye que los clientes cuentan con un gran poder de negociación por ser los dueños de las plantas de maduración, pero a raíz de que hay empresas solidas 
que cuenta con una marca sólida, el poder de negociación de los clientes tiende a ser medio y bajo.

\section{Rivalidad}

1. Estructura de la industria: De acuerdo al análisis realizado en el mercado peruano, la industria es consolidada ya que son pocos los competidores grandes (Ver Anexo 3). Por lo tanto, los líderes generan que la rivalidad tienda a ser baja en el mercado de Perú. Asimismo, a nivel internacional, las empresas líderes cuentan con convenios con las empresas minoristas, haciendo que la rivalidad en el mercado internacional tienda a que sea baja.

2. Demanda en la industria: Para analizar este factor en la industria agroindustrial, se realiza tomando como ejemplo la demanda de los arándanos. Entonces, de acuerdo a Bell y Kindred (2016)," los arándanos han experimentado a nivel internacional desde el 2008 al 2014, un crecimiento promedio de 13\% en Norteamérica, 32\% en Europa y $49 \%$ en Asía-Pacifico" (p.8).

Por lo tanto, se sostiene que la demanda de arándanos está en constante crecimiento, por lo que generaría que la rivalidad sea baja, ya que cuando hay crecimiento de la demanda las empresas que forman parte del sector van a vender más sin buscar quitar participación de mercado a los demás competidores.

3. Diferenciación del Producto: El producto en cuestión que ofrece la industria son las frutas, razón por la cual lograr una diferenciación es complicado. En la industria de frutas, las empresas consolidadas han desarrollado una estrategia para lograr una diferenciación a través de la creación de una marca que permita expresar la calidad y consistencia de la organización, permitiendo que clientes minoristas y finales tengan una mayor identificación con las empresas líder.

Para el presente factor se argumenta que al generarse una diferenciación a través de marca, la rivalidad en la industria es baja, porque no es fácil lograr diferenciarse ya que implica utilizar muchos recursos que la mayoría de empresas del sector no están dispuestas a realizar.

4. Costo de Cambio: Se sostiene que en la industria en general el costo de cambio es bajo porque los clientes minoristas podrían cambiar de proveedor sin mayor dificultad; sin embargo, en el caso de empresas líder dentro de la industria, la mayoría de compradores del sector quiere desarrollar relaciones de largo plazo y no perderse los 
beneficios que ofrecen, generando que el costo de cambio sea alto y por lo tanto la rivalidad se baja ya que difícilmente van a querer cambiarse.

5. Barreras de Salida: De acuerdo al análisis realizado a la industria, se sostiene que en esta industria es necesario realizar grandes inversiones en maquinaria, equipos e instalaciones para poder operar, porque la producción que se realiza es de grandes volúmenes, constituyéndose esto como una barrera de salida alta. Asimismo, las obligaciones laborales que hay que cumplir con una gran mano de obra, generan que salirse de la industria se deba asumir muchos costos tales como pago de indemnizaciones o liquidaciones, convirtiéndose en una barrera de salida alta ya que es difícil dejar a gran número de personas sin trabajo.

Se concluye que la rivalidad en la industria es alta dado las grandes barreras de salida; sin embargo, tiende a ser baja para las empresas líder del sector.

\subsubsection{Determinación y sustentación de Oportunidades y Amenazas}

Según Griffin (2011) afirma: “ Las oportunidades organizacionales son las áreas que pueden generar más alto desempeño y las amenazas organizacionales son áreas que aumentan la dificultad de una organización se desempeñe a nivel superior” (p.241).

Habiendo realizado el análisis del macro entorno y el micro entorno, a través de la herramienta del PEST y las cinco fuerzas de Porter, respectivamente, se han identificado las siguientes Oportunidades y Amenazas más importantes en el sector:

\section{Oportunidades}

- Mayor interés de los consumidores a nivel mundial por alimentos frescos y saludables, esto es una oportunidad porque se crea una tendencia hacia productos sanos. (Bell y Kindred, 2016)

- Existen barreras altas de entrada a la industria, genera una oportunidad porque ayuda a las empresas del sector a poder consolidarse.

- Industria ofrece alimentos con beneficios únicos para la salud, genera oportunidad porque es una industria que ofrece productos de alta calidad. (Bell y Kindred, 2016) 
- Se incrementa la aceptación de productos orgánicos entre los consumidores a nivel internacional, representa una oportunidad porque permite generar una nueva categoría de productos. (Bell y Kindred, 2016)

- El Tipo de Cambio en Perú se encuentra estable, genera una oportunidad para el sector exportador de poder realizar proyecciones en caso se decida importar máquinas. (Gestión, 2019)

\section{Amenazas}

- Crecimiento económico de Perú se redujo debido a caída en la inversión interna y en los precios de materias primas, representando una amenaza, ya que a mayor crecimiento del PBI, mayor crecimiento de las exportaciones.

- Constante enfrentamiento entre poder legislativo y poder ejecutivo, representa una amenaza porque de no haber estabilidad en el plano político, las inversiones se paralizarán. (El Comercio, 2019)

- Frutas y verduras están asociadas con la vida, cualquier desperfecto puede ocasionar alejamiento definitivo del consumidor, esta situación genera una amenaza para todo el sector. (Bell y Kindred, 2016)

- Fenómeno climatológico El Niño que ocurre en el noroeste de Perú cada cierto tiempo, representa una amenaza porque la magnitud de este fenómeno no es posible cuantificar del todo. (Bell y Kindred, 2016)

- Clientes cuentan con gran poder de negociación por ser los dueños de las plantas de maduración, generando una amenaza, ya que se depende de ellos para finalizar el proceso de maduración. (Bell y Kindred, 2016) 


\section{CAPÍTULO II: FORMULACIÓN DE LA ESTRATEGIA}

\subsection{Desarrollo y sustentación de la Matriz EFI}

Según David y David (2017): “ Esta herramienta para la formulación de estrategias sintetiza y evalúa las fortalezas y debilidades más importantes encontradas en las áreas funcionales de una empresa"(p.116).

De acuerdo al análisis realizado a la empresa Camposol, se concluye que tiene una posición interna sólida y que tiene la suficiente capacidad para hacer frente a sus debilidades, puesto que ha obtenido un puntaje de 2.81, puntaje superior al promedio que es de 2.5. Solo por mencionar algunas fortalezas superiores, la empresa Camposol cuenta con su propia comercializadora y cuenta con gran gestión en programación y almacenamiento de pedidos.

Tabla 2.1

Matriz de evaluación de factores internos

\begin{tabular}{|l|l|l|}
\hline VALOR & CALIFIC. & V.POND. \\
\hline
\end{tabular}

\section{FORTALEZAS}

1.- Know how de gestión de los campos de cultivos logrando rendimiento alto en zonas desérticas

2.- Desarrollo de economías de escala a nivel de empresa líder en su industria

3.- Gran gestión en programación, cronograma de pedidos y almacenamiento

4.- Propia comercializadora, convirtiéndose también en distribuidor de sus mismos productos

5.- Constante búsqueda de desarrollo de relaciones a largo plazo con los clientes.

\section{DEBILIDADES}

1.- Mayor parte de los campos de cultivo se encuentran en el noroeste de Perú

2.- Se cuenta con mano de obra escasa en período de mayor producción

3.- No se cuenta con las instalaciones de maduración, no pudiendo lograr la maduración final

4.- Marca es el mismo nombre de la compañía, cualquier desperfecto perjudica reputación de la empresa

5.-Servicio de post venta con un poco de limitaciones, ya que se realiza en rubro de frutas

Fuente: David, F (1997)

Elaboración propia 


\subsection{Desarrollo y sustentación de la matriz EFE}

Según Wheelen y Hunger(2013)afirma: “ El uso de la matriz EFE es una manera de organizar los factores externos en las categorías generalente aceptadas de oportunidades y amenazas y analizar que tan bien la gestión de una empresa en partícular esta respondiendo a estos factores"(p.138).

De acuerdo al análisis realizado, se sostiene que la empresa Camposol, cuenta con la capacidad de aprovechar las oportunidades de forma solvente y hacer frente a las amenazas de la mejor manera, puesto que ha obtenido una puntuación de 3.13, puntuación muy superior a la media que es de 2.5. Asimismo, como principal oportunidad, es que existe un mayor interés de los consumidores finales por alimentos saludables, y como principal amenaza, es la desaceleración económica que actualmente hay en el país.

Tabla 2.2

Matriz de evaluación de factores externos

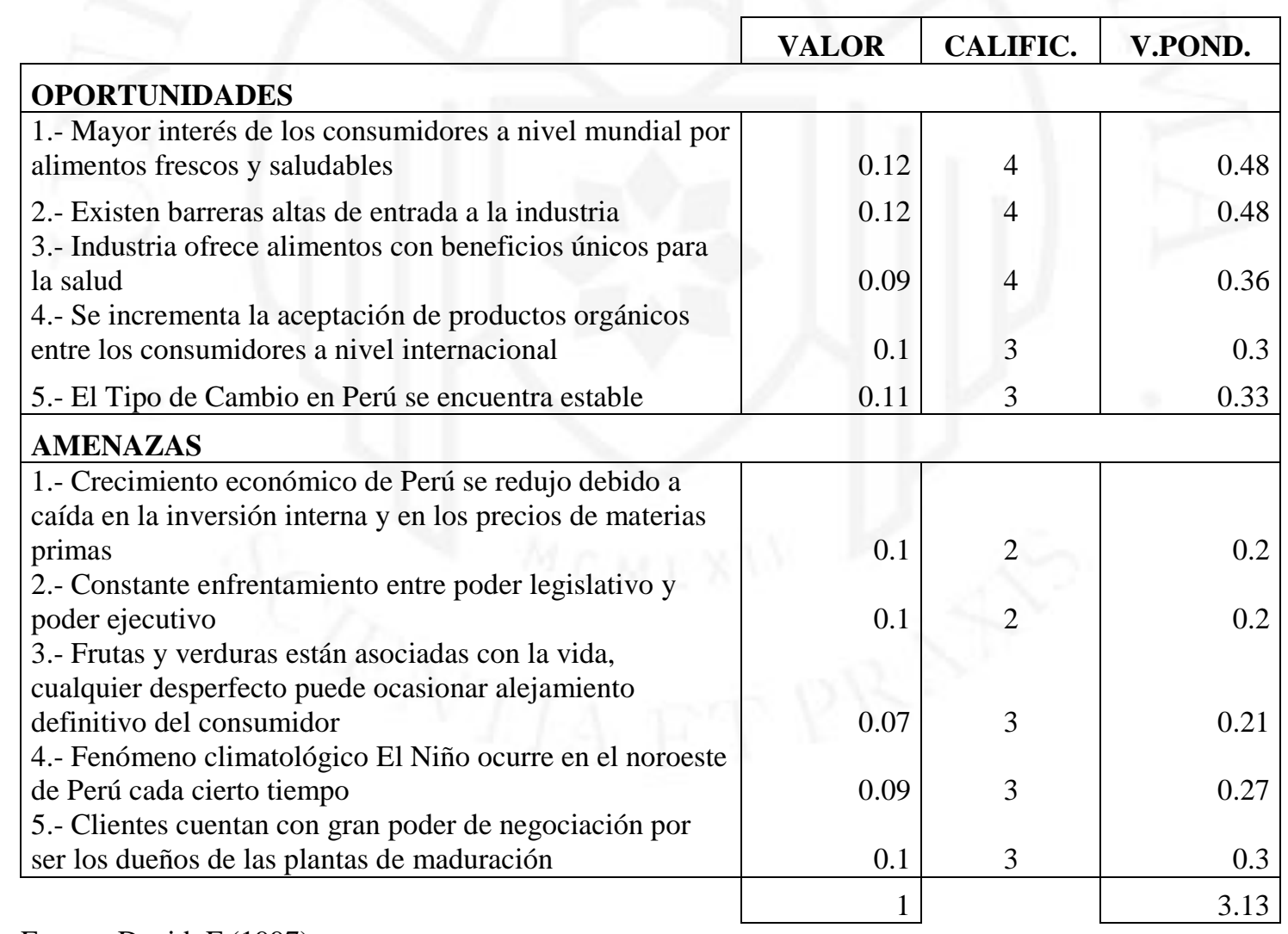

Fuente: David, F (1997)

Elaboración propia 


\subsection{Matriz de la Estrategias Genéricas (Sustento)}

Según David y David( 2017), afirman: "Las estrategias permiten que las organizaciones obtengan una ventaja competitiva con base en tres ejes fundamentales: liderazgo en costos, diferenciación y enfoque" (p.144).Una estrategia genérica es aquella estrategia que se puede desarrollar en cualquier industria, sin importar el rubro al cuál se dedica la empresa o el producto o servicio que ofrezca.

Figura 2.1

Matriz de las Estrategias Genéricas de Michael Porter

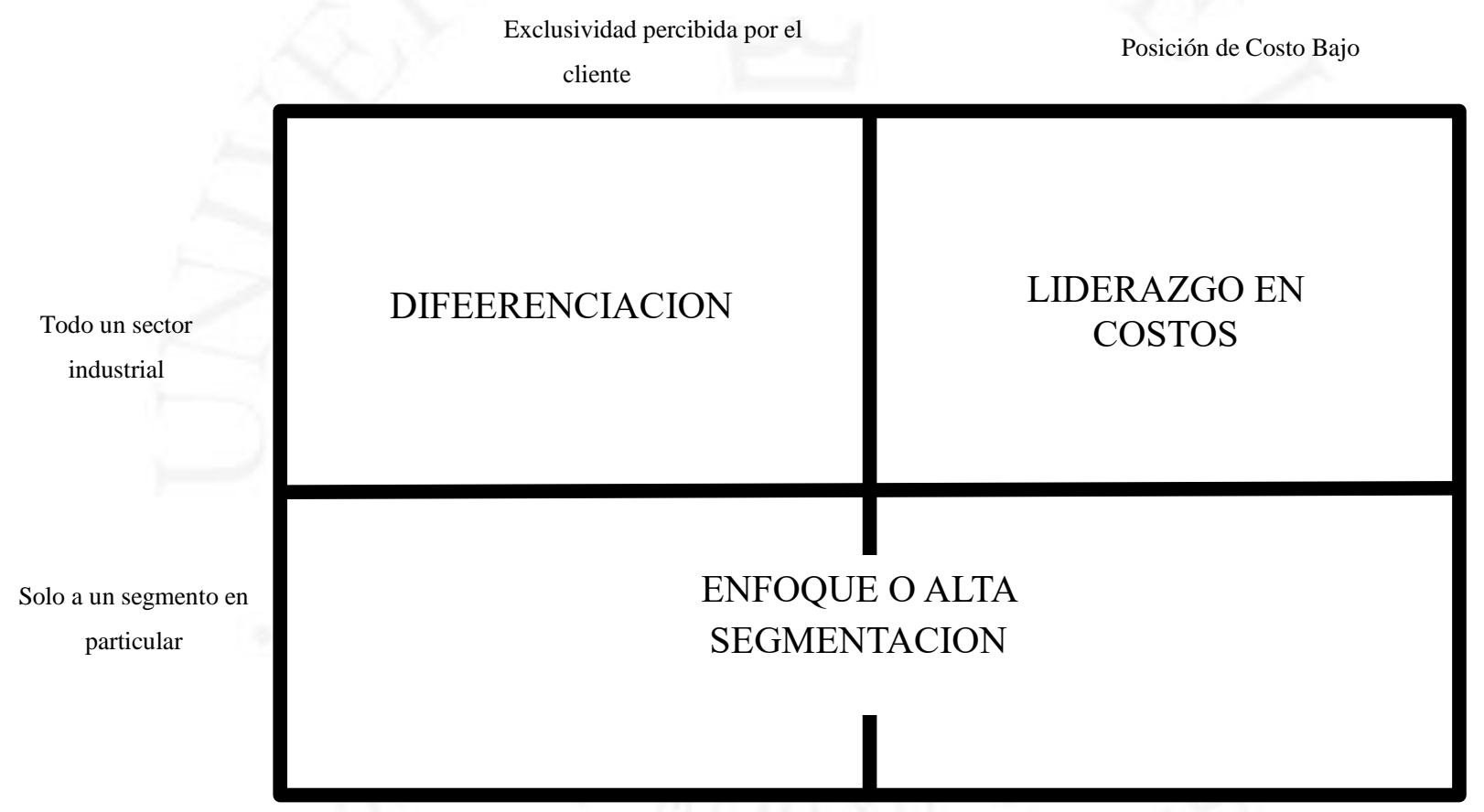

Fuente: Porter(2010)

Elaboración propia

En el presente análisis se ha determinado que la estrategia genérica que la empresa Camposol ha implementado, es la siguiente:

\section{"Liderazgo en Costos + Diferenciación"}

La organización realiza esfuerzos en generar una diferenciación basándose en otorgar una mayor calidad, dado que sus productos cuentan con una mayor ventaja al venir mayormente de una sola área, razón por la cual decidieron crear su estrategia de 
marca, creando "Camposol" y "Sol Produce". Asimismo, la empresa Camposol se diferencia porque ejerce un fuerte control en toda su cadena de producción, logrando estandarizar todos los procesos. (Bell y Kindred, 2016)

Se sostiene que la empresa cuenta con una posición de liderazgo en costo, porque la empresa logra estandarizar todos los procesos, genera economías de escala y aprendizaje, y cuenta con gran gestión de stocks para pedidos.

Finalmente estas dos ventajas competitivas llevan a la empresa a también destacar por brindar una máxima satisfacción al cliente.

\subsection{Matriz FODA (Sustento)}

Es llegar a conclusiones a partir de sus listas sobre la situación general de la empresa y convertirlas en acciones estrategicas con el fin de que la estrategias se ajuste mejor a las fortalezas y las oportunidades del mercado, corregir las debilidades importantes y defenderse de las amenazas externas. (Thompson, Gamble, Peteraf, y Strickland III, 2015, págs. 85-86)

A continuación se sustenta la Matriz FODA para la empresa Camposol: 
Tabla 2.3

Matriz FODA cruzado

\begin{tabular}{|c|c|c|}
\hline & FORTALEZAS - F & DEBILIDADES - D \\
\hline $\begin{array}{l}\text { MATRIZ FODA EMPRESA } \\
\text { CAMPOSOL }\end{array}$ & $\begin{array}{l}\text { F.1 Know How de gestión en los } \\
\text { campos de cultivos. } \\
\text { F.2 Desarrollo de economías de } \\
\text { escala como empresa líder de } \\
\text { industria. } \\
\text { F.3 Gran gestión en programación, } \\
\text { cronograma y almacenamiento de } \\
\text { pedidos. } \\
\text { F.4 Propia comercializadora, ahora } \\
\text { es distribuidor de sus mismos } \\
\text { productos. }\end{array}$ & $\begin{array}{l}\text { D.1 Concentración de la mayor parte } \\
\text { de } \\
\text { campos de cultivo en Perú } \\
\text { D. } 2 \text { Mano de Obra escasa } \\
\text { D. } 3 \text { No se cuenta con las } \\
\text { instalaciones de maduración, no } \\
\text { pudiendo lograr la maduración final. } \\
\text { D.4 Marca es el mismo nombre de la } \\
\text { compañía, cualquier desperfecto } \\
\text { perjudica reputación de la empresa }\end{array}$ \\
\hline $\mathbf{O P}$ & ESTRATEGIA - FO & DO \\
\hline $\begin{array}{l}\text { O.1 A nivel mundial, mayor } \\
\text { interés por productos frescos } \\
\text { y saludables. } \\
\text { O.2 Existen barreras altas de } \\
\text { entrada a la industria. } \\
\text { O.3 Mayor aceptación a } \\
\text { nivel mundial de los } \\
\text { alimentos orgánicos. } \\
\text { O.4 El Tipo de Cambio en } \\
\text { Perú se encuentra estable. }\end{array}$ & $\begin{array}{l}\text { F1 - O3 : Aprovechar Know How } \\
\text { en gestión de campos de cultivo } \\
\text { para desarrollar campos de cultivo } \\
\text { orgánicos en al menos principales } \\
\text { frutas y verduras. } \\
\text { F3 - O4 : Aprovechar tipo de } \\
\text { cambio estable para adquirir } \\
\text { sistema o software que sincronize } \\
\text { abastecimiento de empresa } \\
\text { Camposol con área de } \\
\text { requerimiento de los clientes } \\
\text { minoristas. } \\
\text { F4 - O2 : Aprovechar las barreras } \\
\text { de entrada alta a la industria, } \\
\text { con el objetivo de que la } \\
\text { comercializadora realice mayor } \\
\text { penetración de mercado en sus } \\
\text { ventas a minoristas. }\end{array}$ & $\begin{array}{l}\text { D3 - O4 : Aprovechar tipo de } \\
\text { cambio estable para comprar equipos } \\
\text { de } \\
\text { maduración propios. } \\
\text { D4 - O1 : Posicionar marca y } \\
\text { nombre de la compañía como } \\
\text { empresa líder } \\
\text { de alimentos frescos y sanos. } \\
\text { D2 -O2 : Asegurar la mano de obra } \\
\text { que ya se tiene, y buscar como traer } \\
\text { mano de obra de industrias en las } \\
\text { cuáles las barreras de entrada sean } \\
\text { bajas. }\end{array}$ \\
\hline AMENAZAS - A & ESTRATEGIA - FA & A - DA \\
\hline $\begin{array}{l}\text { A.1 Crecimiento económico } \\
\text { de Perú se redujo debido a } \\
\text { caída en la inversión interna } \\
\text { y en los precios de materias } \\
\text { primas. } \\
\text { A. } 2 \text { Clientes cuentan con } \\
\text { gran poder de negociación } \\
\text { por ser dueños de las plantas } \\
\text { de maduración. } \\
\text { A.3 Fenómeno climatológico } \\
\text { El Niño ocurre en el } \\
\text { noroeste de Perú cada cierto } \\
\text { tiempo. } \\
\text { A.4 Asociación de vida en } \\
\text { las frutas y verduras. }\end{array}$ & $\begin{array}{l}\text { F1 - A2 : Crear alianza con cliente } \\
\text { para entregarle frutas nuevas } \\
\text { de gran valor, aprovechando el } \\
\text { Know How de empresa líder en } \\
\text { campos de cultivo. } \\
\text { F4 - A4 : Comercializadora realice } \\
\text { campañas de publicidad y } \\
\text { marketing para hacer llegar el } \\
\text { mensaje de que la empresa } \\
\text { Camposol solo produce frutas de } \\
\text { gran valor y que cuentan con todas } \\
\text { las inspecciones de salud } \\
\text { correspondientes. } \\
\text { F3 - A3 : Asegurar el } \\
\text { cumplimiento y entrega de los } \\
\text { pedidos antes de llegada del } \\
\text { fenómeno El Niño, aprovechando } \\
\text { gran gestión en programación de } \\
\text { pedidos. }\end{array}$ & $\begin{array}{l}\text { D1 - A3 : Buscar más campos de } \\
\text { cultivos fuera de Perú o buscar zonas } \\
\text { de cultivo en Perú donde el impacto } \\
\text { del fenómeno El niño, no sean muy } \\
\text { fuerte. } \\
\text { D2 - A1 : Promover imagén o } \\
\text { reputación de empleador serio y } \\
\text { responsable en Perú. } \\
\text { D3 - A2 : Fortalecer relaciones de } \\
\text { confianza con los clientes minoristas } \\
\text { que ya se tiene una alianza. }\end{array}$ \\
\hline
\end{tabular}

Fuente: Thompson (1998).

Elaboración propia 


\subsection{Definición y sustentación de la Visión, Misión y Políticas}

La Visión representa una declaración formal de hacia dónde quiere llegar la empresa en un determinado tiempo. A continuación se detalla la visión actual de la empresa Camposol:

Visión: "Ser el proveedor preferido y superior de alimentos saludables y frescos para familias de todo el mundo". (Camposol, 2019)

Con respecto a la Misión, este significa el propósito de la organización; es decir, la razón de ser de la empresa y a que se dedica. A continuación se muestra la misión actual de la empresa Camposol, también se realiza una propuesta de nueva misión y el sustento respectivo:

Misión: "Proveer a los consumidores de todo el mundo alimentos saludables a través de la excelencia operacional, innovación, prácticas sostenibles; generando un impacto positivo y duradero en el bienestar de las comunidades donde operamos; creando valor constante a largo plazo para nuestros accionistas”. (Camposol, 2019)

Propuesta de Misión: "Suministrar los mejores alimentos frescos y saludables a nuestros clientes a nivel mundial, basándonos en la integridad, respeto, excelencia, trabajo en equipo y austeridad de nuestros colaboradores, y desarrollando excelencia operacional, innovación y prácticas sostenibles en las comunidades donde operamos permitiéndonos desarrollar relaciones de largo plazo y beneficios mayores para la empresa”.

Argumento: La presente propuesta se realiza con un énfasis en los valores con los que cuenta la empresa, porque al estar buscando desarrollar su estrategia de marca, es importante hacer conocer con que principios opera la empresa para obtener de esta manera que la marca logre una posición de confianza en el consumidor final. Asimismo, dado que la empresa está en contacto continuo con las comunidades, es importante resaltar los valores porque permite que los colaboradores sepan la forma en cómo se debe laborar en Camposol.

Respecto a las Políticas, son aquellas reglas bajo la cual se rige una empresa; es decir, es la declaración formal de cómo opera la organización. A continuación se detalla las principales políticas dentro de la empresa Camposol:

- Ningún miembro de la familia Dyer desempeñará funciones operativas en la empresa Camposol. (Bell y Kindred, 2016) 
- Probar constantemente de 15 a 20 nuevos cultivos y variedades cada año. (Bell y Kindred, 2016)

- Todos los trabajadores de granja, plantas de producción y empaque, deben utilizar sus equipos de protección personal. (Camposol, 2019)

- Publicar informes de sostenibilidad verificados por terceros independientes cada año. (Bell y Kindred, 2016)

- Usar eficiente de los recursos para cuidar el medio ambiente y ser socialmente responsable.

\subsection{Definición de los Objetivos Estratégicos de la empresa}

Según Benavides Pañeda (2014) afirma: “ Los objetivos son las metas a las que queremos llegar, son una declaración específica de los resultados que buscamos. Estas metas tienen que ser consistentes e identificadas con el proposito fundamental que guía nuestros esfuerzos”(p.71). Asimismo, señalar que los objetivos estratégicos o Smart, deben ser: Específicos, Medibles, Alcanzables, Relevantes y en un Tiempo Determinado.

A continuación se detallan los objetivos estratégicos de la empresa Camposol:

- Incrementar 3 categorías más a la unidad de negocio de frutas y verduras para el 2021.

- Expandirse a 3 nuevos mercados en el mercado asiático para los próximos 3 años.

- Incrementar fidelización del cliente minorista en un 60\% para el año 2021.

- Aumentar las ventas directas en un 30\% a los minoristas de supermercados chinos para el año 2020.

- Generar 3 nuevas alianzas con clientes minoristas que no tengan relaciones de cultivador en Perú, para los próximos 2 años.

- Elevar gastos de publicidad y marketing en un $20 \%$ para promocionar marca Camposol en el consumidor final, en el año 2020.

\subsection{Redefinición de las Unidades Estratégicas de Negocio (UEN) o creación de nuevas UEN}

De acuerdo al análisis realizado, se sostiene que la empresa Camposol no ha logrado diferenciar con claridad sus unidades estratégicas de negocio o que la empresa podría mejorar la definición exacta de cada una de estas. Por lo tanto, se realiza un planteamiento 
competitivo en el cual se ha decidido redefinir la unidad estratégica de negocio de Trading, porque esta unidad no está bien planteada, ya que para que se considere como una unidad estratégica, esta tuviera que ofrecer sus servicios a terceros, situación que en la actualidad no ocurre, sino que más bien es utilizada para comercializar sus propios productos de forma eficiente. Por lo tanto, se propone que el Trading sea tomado como un área de apoyo a las diferentes unidades de negocio.

A continuación se propone la siguiente redefinición de unidades estratégicas de negocio para la empresa Camposol:

Unidad Estratégica de Negocio de Frutas: Esta unidad está conformado por categorías de fruta tales como aguacates, arándanos, mandarinas, uvas y mangos. Estas frutas son comercializadas como productos frescos, y van especialmente a los mercados de Estos Unidos, Europa y China. (Bell y Kindred, 2016)

Unidad Estratégica de Negocio de Verduras: La presente unidad se enfoca en la comercialización de las verduras que posee la empresa Camposol, tales como los espárragos blancos, espárragos verdes, pimientos y la quinua. De igual manera, estas verduras con vendidas como productos frescos en los principales mercados internacionales. (Bell y Kindred, 2016)

Unidad Estratégica de Mariscos: Esta unidad está enfocada en la comercialización de camarones, langostinos, calamares y vieiras. Los mercados internacionales a los que llegan los productos marinos son a Estados Unidos, Europa y Asia. (Bell y Kindred, 2016)

\subsection{Propuesta y sustentación de estrategias en el ambiente Global, Corporativas de Negocios y Funcionales}

\section{Estrategias Globales}

Estas estrategias son aquellas que se utilizan para ingresar a mercados internacionales, ya que el mercado nacional puede haber quedado insuficiente para el objetivo de obtener mayores beneficios. De igual manera, (Hill, Jones, y Schilling, 2015)sostienen que: "Las estrategias globales "sufren 2 presiones competitivas: las presiones para bajar los costos y las presiones para responder a lo local” (p.258). 
De acuerdo al análisis realizado, se ha identificado que estrategia está utilizando la empresa Camposol:

Entonces, se ha identificado que la empresa Camposol, para entrar a los mercados internacionales está utilizando una estrategia de Estandarización Global, porque el producto, en este caso frutas, es un producto estandarizado o base; es decir, se venden las mismas frutas a todos los países del mercado internacional, generando que la presión por adaptarse a lo local, sea bajo; sin embargo, también se ha identificado como característica de esta estrategia, es que en la industria existe presión alta por bajar los costos, ya que se producen grandes volúmenes de estos productos y es necesario desarrollar economías de escala para generar beneficios.

De igual manera, también se ha identificado que la empresa Camposol, al momento de entrar a China, ha desarrollado una Estrategia Trasnacional, porque la empresa decidió adaptar el tamaño de frutas tales como el aguacate y el arándano, esto debido a que en China el consumidor valora más una fruta grande y no tanto el sabor, generando que pague más, por lo tanto la presión por adaptarse a las condiciones locales del mercado chino, son altas; asimismo, la presión por bajar costos es alta, porque continuamente se deben desarrollar economías de escala para hacer frente a la gran demanda mundial de frutas.

\section{Estrategias Corporativas}

De acuerdo a Robbins y Coutler(2014) afirman: “ La estrategia corporativa determina en que líneas de negocio opera o desea operar la empresa y qué quiere lograr al participar en ellas"(p.245).

A continuación se desarrolla como la empresa Camposol ha aplicado estas estrategias:

\section{1.- Estrategias Intensivas}

Penetración de mercado: La empresa Camposol ha desarrollado esta estrategia porque ha venido intensificando la venta de sus productos a través de su propia comercializadora, logrando vender grandes cantidades de frutas.

Desarrollo de Mercado: Con relación a la empresa Camposol, se sostiene que ha desarrollado esta estrategia porque no hace mucho tiempo ha ingresado a China a vender frutas tales como aguacates y arándanos, productos actuales de la empresa. 
Desarrollo de Producto: De acuerdo al análisis realizado para la empresa Camposol, se sostiene que ha desarrollado esta estrategia porque anteriormente todos sus productos de la unidad de frutas y verduras se vendían como enlatados, en la actualidad se comercializan como productos frescos.

\section{2.- Estrategias de Integración}

Integración Vertical hacia delante: Con respecto a la empresa Camposol, se sostiene que ha desarrollado esta estrategia porque creó su propia comercializadora para vender sus propios productos, teniendo oficinas en Estados Unidos, Europa y Asia, y de esta manera ya no depende de los distribuidores o intermediarios para comercializar sus productos. Asimismo, se sostiene que ha desarrollado esta estrategia, debido a que la propia empresa realiza las labores requeridas para hacer llegar el producto a destino.

\section{3.- Diversificación}

Diversificación Relacionada: De acuerdo al análisis realizado al caso, se sostiene que la empresa Camposol ha desarrollado esta estrategia porque dentro de la categoría de frutas y verduras, la empresa inicialmente empezó comercializando solo espárragos, en cambio actualmente cuenta con una variedad de productos dentro esta categoría tales como aguacates, arándanos, mangos, uvas, mandarinas, etc., que comparten una misma cadena de valor o ciertos puntos específicos de esta.

Diversificación No Relacionada: En relación al caso analizado, se afirma que la empresa estudiada, ha desarrollado esta estrategia porque en el año 2015 creó su unidad de negocio de Mariscos; es decir, desarrolló un nuevo negocio en otra industria diferente a la de frutas y verduras, y de esta manera las actividades que se desarrollan entre ambas unidades no tienen muchas características en común dentro de la cadena de valor.

Asimismo, se propone que la empresa Camposol realice las siguientes estrategias corporativas, con el objetivo de generar aún más valor:

- La empresa Camposol debe realizar integración horizontal para comprar o adquirir a un competidor directo externo para que la producción de la empresa no dependa mayormente de la producción de Perú.

- Como propuesta de desarrollo de producto, se plantea desarrollar formato para vender frutas en paquetes de dos unidades. 
- Se propone que la empresa busqué otros mercados en Asia aparte de China, para desarrollar una estrategia de desarrollo de mercado.

- Crear alianza con otra empresa en el sector de jugos para crear uno de arándanos, con el objetivo de desarrollar una estrategia de diversificación relacionada, dado que ya cuenta con los arándanos.

- Desarrollar productos como mermeladas con las mermas de las diversas frutas tales como los arándanos, aguacates, mangos, uvas y mandarina, con el objetivo de desarrollar una estrategia de diversificación relacionada.

- Crear cadenas de markets conceptuales con giro en productos sanos, y de esta manera ofrecer propias frutas y verduras, con el objetivo de desarrollar una estrategia de diversificación no relacionada.

\section{Estrategias Funcionales}

Benjamín y Fincowsky(2009) sostienen que: "Las estrategias funcionales están relacionadas con las funciones de las unidades administrativas" (p.9). Estas tienen la finalidad de lograr un desempeño superior en cada una de las áreas, y de esta manera lograr una ventaja competitiva.

Entonces, de acuerdo al análisis realizado, se plantean las siguientes estrategias en sus respectivas áreas:

\section{Recursos Humanos}

- Realizar campañas de capacitación a los colaboradores que trabajan en planta y granjas.

- Efectuar pagos por remuneración en base al desempeño, en áreas como producción o ventas.

- Desarrollar equipos auto dirigidos; es decir, que el mismo equipo programe sus actividades en planta y equipo.

\section{Marketing}

- Incrementar inversión en punto de venta ubicados en los supermercados.

- Ofrecer precios competitivos a los clientes.

- Desarrollar relaciones de largo plazo con los clientes a través de la marca.

\section{Producción}

- Desarrollar economías de escala y economías de aprendizaje. 
- Invertir en tecnología para desarrollar personalización masiva. 


\section{CAPÍTULO III: IMPLEMENTACIÓN ESTRATÉGICA}

\subsection{Evaluación del rediseño o no rediseño de la estructura organizacional de la empresa (Sustento)}

Después de haber realizado el análisis respectivo, se ha identificado que la empresa Camposol cuenta con una estructura organizacional vertical, porque las decisiones o estrategias más importantes son realizadas por los mandos altos de la organización y también la toma de decisiones es llevada a cabo desde Perú, matriz de operación de la empresa Camposol. Por lo tanto se propone que los mandos medios tomen un rol más protagónico en las decisiones; es decir, que los mandos altos deleguen las tareas o actividades con sus colaboradores para que de esta manera se genere una sinergia entre todos para crear nuevas estrategias que generen valor a la empresa, y de esta manera la estructura se volvería horizontal, ya que la comunicación sería más sencilla entre los miembros de la empresa. Para profundizar esta propuesta, Daft y Marcic (2010) afirman:

“ La coordinación se refiere a la calidad de la colaboración entre los departamentos. Sin coordinación, la mano izquierda de la empresa no actuará en armonía con la derecha, lo cual ocasionará problemas y conflictos”(p.267).

Asimismo, se propone dividir las unidades estratégicas de negocio de la empresa según frutas, verduras y mariscos; es decir, cada producto diferente con su propia unidad de negocio, por lo tanto sería una estructura organizacional por producto, en la cual Hill, Jones, y Schilling (2015) afirman : "Para mantener los costos tan bajos como sea posible, las funciones de apoyo de la cadena de valor, permanecen centralizadas en la cima de la organización, y los diferentes grupos de producto comparten sus servicios”(p.423).

Entonces, dado que se ha propuesto una nueva estructura organizacional, es necesario capacitar a los colaboradores de los niveles medios y altos para que se alineen a esta nueva estructura y cumplir el objetivo de aportar en la estructura nueva.

A continuación se presenta la estructura organizacional propuesta para la empresa Camposol: 
Figura 3.1

Diseño de la Estructura Organizacional

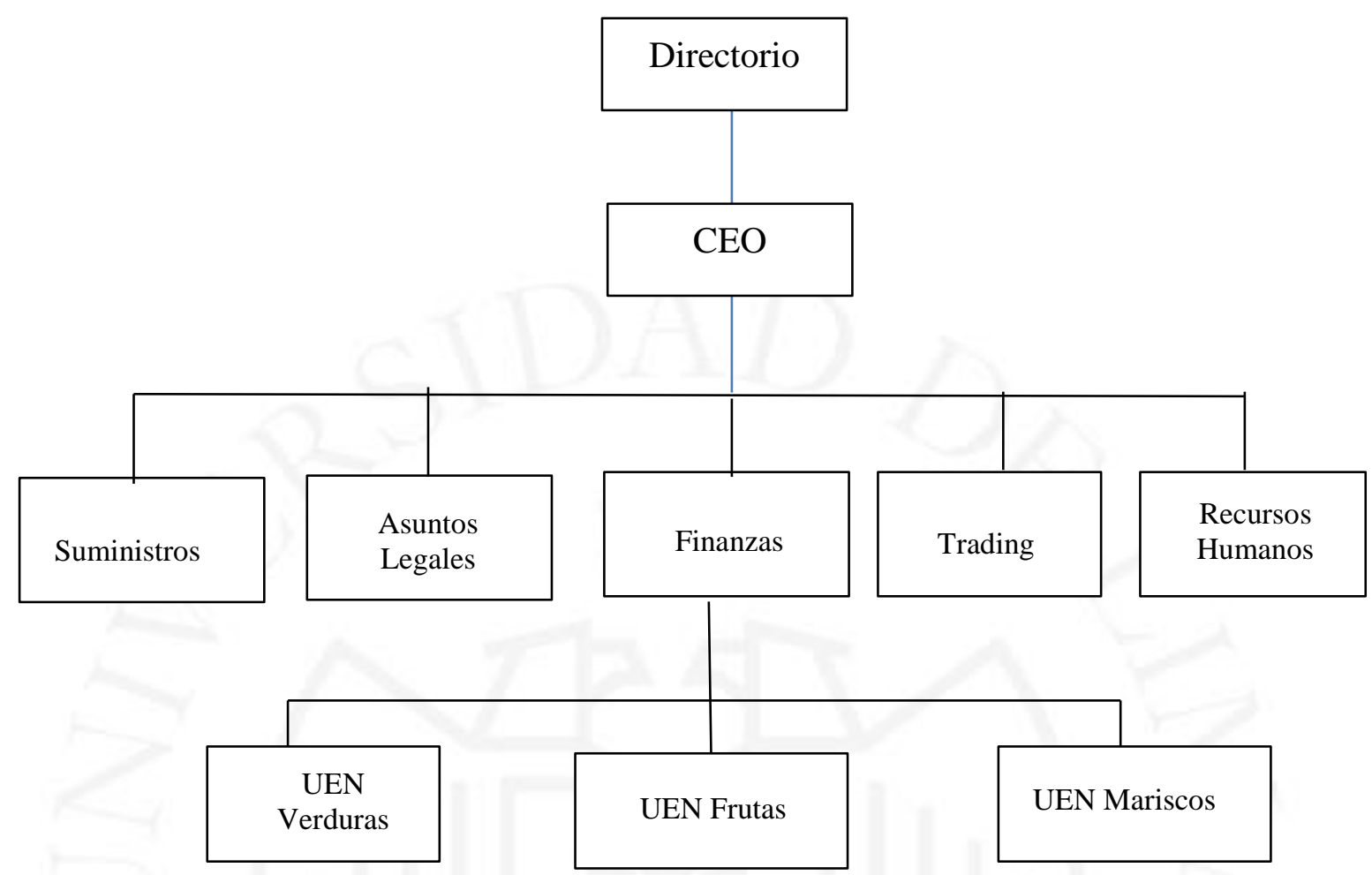

Fuente: Hill, Jones, y Schilling (2015)

Elaboración propia

\subsection{Propuesta de cambios para mejorar la implementación de estrategias en la empresa}

De acuerdo a las propuestas planteadas en el punto 2.8, se ha tomado en cuenta que para mejorar el desempeño de las estrategias corporativas propuestas, se debe realizar las siguientes implementaciones para cada estrategia:

Propuesta de Implementación para Desarrollo de Mercado: Realizar una investigación profunda para conocer cómo es el mercado al cuál se quiere ingresar.

Propuesta de Implementación para Integración Horizontal: Estudiar cuánta participación de mercado tiene cada competidor que se considere que tienen potencial para generar valor. Asimismo, conocer con que fortalezas cuenta.

Propuesta de Implementación para Desarrollo de Producto: Desarrollar una evaluación para determinar que material es el más adecuado para los paquetes nuevos que se proponen utilizar. 
Propuesta de Implementación para Diversificación no Relacionada: Evaluar lugares o puntos estratégicos donde el negocio de markets con productos naturales, sea demandado con facilidad.

Propuesta de Implementación para Diversificación Relacionada: Establecer términos y condiciones de la alianza con la empresa socia para desarrollar los jugos de fruta. 


\section{CAPÍTULO IV: CONTROL ESTRATÉGICO}

\subsection{Diseño de un Mapa Estratégico de Control para la empresa}

De acuerdo a Kaplan y Norton(2001) afirman: “El mapa estratégico deja bien explícitas las hipótesis de la estrategia" (p.69). Esta herramienta permite visualizar diferentes áreas de control junto con sus respectivos indicadores de gestión. Las 4 áreas o perspectivas que se necesitan para realizar el control estratégico en una empresa son las siguientes: Financiera, en el Cliente, Procesos Internos y Aprendizaje o Innovación.

De acuerdo al análisis realizado, se propone el siguiente Mapa Estratégico para la empresa Camposol:

Figura 4.1

Mapa Estratégico de empresa Camposol

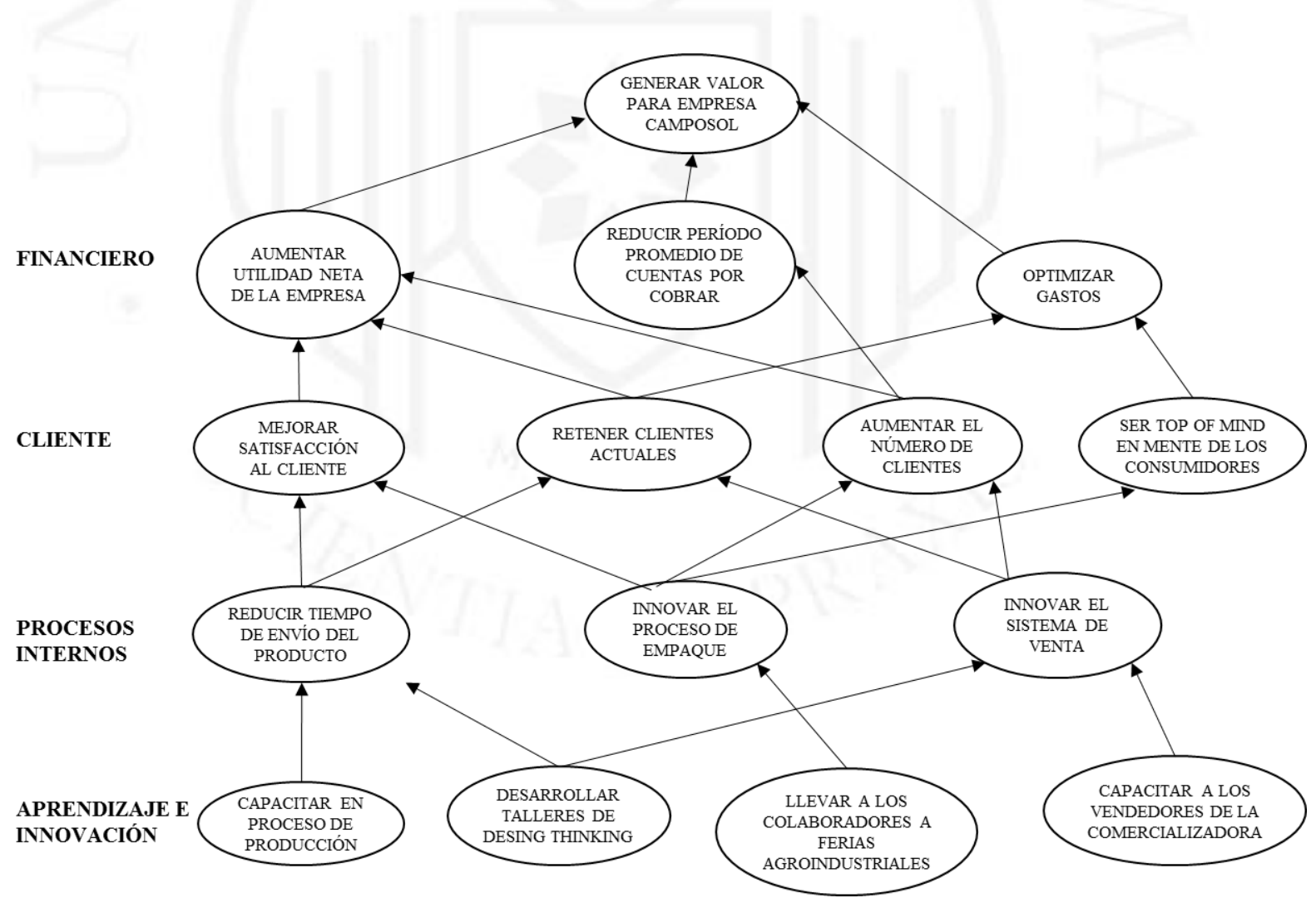

Fuente: Kaplan y Norton (2001)

Elaboración propia 


\subsection{Desarrollo de un Cuadro de Mando Integral con un mínimo de diez índices de gestión}

De acuerdo a Olve, Roy, y Wetter (2000), sostienen: "El cuadro de mando integral reúne diferentes tipos de indicadores en una única visión global de todo el negocio. Es importante que esta visión describa lo que la dirección realmente quiere poner en el punto de mira" (p.169).

Tabla 4.1

Cuadro de Mando Integral empresa Camposol

\begin{tabular}{|c|c|c|}
\hline PERSPECTIVA & OBJETIVOS & INDICADORES \\
\hline Financiera & $\begin{array}{c}\text { Aumentar la utilidad neta } \\
\text { en un } 10 \% \text { para el año } 2020 \\
\text { Optimizar gastos en un } 5 \% \\
\text { para el año } 2020 \\
\text { Reducir período de Cuentas } \\
\text { por cobar en } 4 \text { días para el } \\
\text { año } 2020\end{array}$ & $\begin{array}{c}\frac{\Delta \% \text { Util. Neta 2020 - Util. Neta 2019 }}{\text { Util. Neta 2020 }} \\
\frac{\Delta \% \text { Costos y Gastos de Producción 2020 - Costos }}{\text { y Gastos de Producción } 2019} \\
\text { Costos y Gastos de Producción } 2020 \\
\frac{\Delta \text { Días Prom Cobro } 2020 \text { - Días Prom Cobro }}{\underline{2019}} \\
\text { Días Prom Cobro } 2020\end{array}$ \\
\hline Cliente & $\begin{array}{l}\text { Incrementar el número de clientes } \\
\text { en un } 10 \% \text { para el año } 2020 \\
\text { Ser marca Top of Mind para el año } \\
2020 \\
\text { Mejorar satisfacción del cliente en } \\
\text { un 85\% al finalizar el } 2020 \\
\text { Ofrecer precios competitivos } \\
\text { a los clientes para el año } 2020\end{array}$ & $\begin{array}{l}\frac{\Delta \% \text { \# Clientes 2020 - \# Clientes } 2019}{\text { \# Clientes } 2020} \\
\text { Ranking de marcas Top Of Mind marcas del } 2020 \\
\frac{\Delta \% \text { Clientes Satisfechos 2020 - \% Clientes }}{\% \text { Clientes Satisfechos } 2020} \\
\frac{\text { Patisfechos 2019 }}{\text { Precio ofrecido por la empresa Camposol }} \\
\text { Precio promedio del mercado }\end{array}$ \\
\hline Procesos Internos & $\begin{array}{c}\text { Reducir tiempo de espera del } \\
\text { pedido de } 3 \text { días a } 1 \text { día para el año } \\
2020 \\
\text { Impulsar la venta online para } \\
\text { el año } 2020 \\
\text { Innovar en } 5 \text { presentaciones de } \\
\text { empaque } \\
\text { para el año } 2020\end{array}$ & $\begin{array}{c}\frac{\text { Tiempo espera } 2020 \text { - Tiempo espera } 2019}{\text { Tiempo espera } 2020} \\
\frac{\text { Número de clientes online } 2020}{\text { Número total de clientes } 2020} \\
\frac{\text { \# Innovaciones empaque 2020 - \# Innovaciones }}{\text { empaque 2019 Innovaciones empaque } 2020}\end{array}$ \\
\hline Aprendizaje & $\begin{array}{r}\text { Capacitar a los vendedores cada } \\
3 \text { meses para aumentar las ventas } \\
\text { en el } 2020 \\
\text { Capacitación en todos los procesos } \\
\text { de producción en el } 2020 \\
\text { Elevar el número de colaboradores } \\
\text { que asisten a ferias agroindustriales } \\
\text { en un } 8 \% \text { para el } 2020\end{array}$ & $\begin{array}{c}\text { Número Total de Capacitaciones en el año } 2020 \\
\frac{\text { \# Total obreros salientes en } 2019}{\# \text { Total obreros nuevos en } 2020} \\
\frac{\Delta \% \text { Colaboradores asistentes ferias } 2020-\%}{\% \text { Colaboradores asistentes ferias } 2019} \\
\end{array}$ \\
\hline
\end{tabular}

Fuente: Kaplan y Norton (2001)

Elaboración propia 


\section{CONCLUSIONES}

Después de haber realizado el presente trabajo sobre la empresa Camposol, estas son las conclusiones más relevantes:

- La empresa Camposol cuenta con una propuesta de valor muy completa, porque no solo ofrece los productos en un volumen grande, sino que tiene la capacidad para otorgar frutas de gran calidad, poder fijar precios competitivos y solventes, y cuenta con una estrategia de marca muy potente que le viene cosechando buenas relaciones con clientes importantes a nivel internacional.

- La decisión de haber creado la comercializadora fue un acierto, porque le permitió poder llegar a nuevos mercados internacionales, sin depender de ningún tercero, y de esta manera poder atender a los minoristas de una mejor manera, debido a que realizó una estrategia de integración vertical hacia delante, convirtiéndose en distribuidor se sus propios productos.

- La rivalidad dentro de la industria en la cual opera la empresa Camposol, es una industria con rivalidad alta, dado que cuenta con barrera de salida muy altas tales como las obligaciones laborales, la inversión alta en maquinaria, equipo y campos de cultivo y las obligaciones con los clientes; sin embargo, para la empresa Camposol tiende a ser bajo la rivalidad porque es la empresa líder en el sector agroindustrial en Perú y es líder en ciertas categorías de frutas a nivel internacional.

- Se ha determinado a través del estudio que el poder de negociación que tienen los clientes minoristas es alto, porque se depende de estos para finalizar el proceso de maduración de las frutas, ya que los minoristas son los dueños de las plantas de maduración; sin embargo, la empresa Camposol ha podido neutralizar esta ventaja de los clientes, a través de las diversas alianzas que ha generado con los minoristas más importantes a nivel internacional.

- La empresa Camposol, cuenta con líderes visionarios que han tenido la capacidad de encontrar oportunidades en situaciones de crisis, porque pudieron diversificarse en varios productos para no depender de uno. 


\section{RECOMENDACIONES}

La empresa Camposol puede seguir mejorando en la labor de sus operaciones, por lo tanto se realiza las siguientes recomendaciones:

- La empresa Camposol, para solucionar el problema de la mano de obra escasa en períodos de producción máxima y pensando en el futuro, debe realizar búsqueda de mano de obra en aquellos sectores que no son formales o en los que las barrera de entrada sean baja, y convencerlos de la formalidad que la organización brinda, dado que es una empresa formal con todos los beneficios de acuerdo a ley.

- Desarrollar campos de cultivos orgánicos en al menos las principales categorías de frutas y verduras que ofrece, le supondría mayores beneficios, puesto que existe cada vez más un segmento más grande que demanda estos productos, dado que tienen como característica que reducen al máximo la contaminación al medio ambiente.

- Crear cadena de market conceptual, en el que se ofrezcan frutas y verduras de máxima calidad o productos sanos en general, puesto que la tendencia hacia consumir productos sigue en franco crecimiento en el país, y sería innovador contar con tiendas de conveniencia en los distritos que cuenten con la cantidad adecuada de consumidores de estos servicios.

- La empresa Camposol, debe realizar la adquisición de mayor cantidad de tierras fuera de Perú, a pesar que ya tiene tierras en Uruguay y Colombia; sin embargo, actualmente la mayor cantidad de sus campos se encuentran focalizados en el noroeste de Perú, y en esa zona cada cierto tiempo se presenta el fenómeno climatológico El Niño, generando el riesgo de que los campos se inunden y que no se puedan cumplir con los acuerdos establecidos.

- La importancia del mercado chino, y en general todo el mercado asiático, presenta una oportunidad muy grande que la empresa Camposol debe seguir desarrollando, debido a que en la actualidad, China es el principal socio comercial del Perú. Por lo tanto, la organización, debe seguir adaptando sus estrategias para atender este mercado y ofrecerle frutas que sean únicas del Perú, pero siempre cumpliendo con sus gustos. 


\section{REFERENCIAS}

América Economía. (19 de 05 de 2019). América Economía. Recuperado de América Economía: https://www.americaeconomia.com/economiamercados/comercio/exportaciones-peruanas-de-frutas-crecieron-95-en-elprimer-trimestre-de

Banco Central de Reserva del Perú. (06 de 2019). Banco Central de Reserva del Perú. Recuperado de Banco Central de Reserva del Perú: Banco Central de Reserva del Perú

Bell, D. E., y Kindred, N. (2016). Camposol ( caso 518-S10). Recuperado de Universidad Harvard, Escuela de Negocios: https://www.harvard.edu/

Benavides Pañeda, J. (2014). Administración. México D.F: Mc Graw Hill.

Benjamín, E., y Fincowsky, F. (2009). Organización de empresas. México D.F: Mc Graw Hill.

Betancourt G., B. (2014). Análisis sectorial y competitividad. Bogotá: Primera Edición.

Camposol. (22 de 08 de 2019). Camposol. Recuperado de Camposol: https://www.camposol.com.pe/

Castillo, N. (03 de 02 de 2019). El Comercio. Recuperado de El Comercio: https://elcomercio.pe/economia/peru/tlc-peru-estados-unidos-cumple-10-anosvigencia-sido-impacto-exportaciones-comex-mincetur-noticia-603978

Daft, R. L., y Marcic, D. (2010). Introducción a la administración. México D.F: Cengage Learning.

David, F. R. (2013). Conceptos de administración estratégica. México: Pearson.

David, F. R., y David, F. R. (2017). Conceptos de administración estratégica. Ciudad de México: Pearson.

El Comercio. (30 de 05 de 2019). El Comercio. Recuperado de El Comercio: https://elcomercio.pe/economia/peru/ccl-nuevo-enfrentamiento-ejecutivocongreso-afectar-crecimiento-e-inversiones-noticia-nndc-640099 
Gestión. (04 de 04 de 2019). Gestión. Recuperado de Gestión:

https://gestion.pe/economia/tlc-peru-china-concluye-primera-rondanegociaciones-optimizar-nndc-263319-noticia/

Gestión. (09 de 06 de 2019). Gestión. Recuperado de Gestión:

https://gestion.pe/economia/dolar-analistas-empresas-elevaron-proyeccion-tipocambio-ano-269594-noticia/

Ghemawat, P. (2007). Estrategia y el panorama empresarial. Madrid: FT Prentice Hall.

Gobierno del Perú. (9 de Abril de 2019). Plataforma digital única del estado peruano.

Recuperado de Plataforma digital única del estado peruano:

https://www.gob.pe/institucion/minagri/noticias/27341-ministra-fabiola-munoz-

afirma-que-con-ampliacion-de-ley-de-promocion-agraria-se-buscara-beneficiara-pequenos-productores

Griffin, R. (2011). Administración. México D.F: Cengage Learning.

Hill, C. W., Jones, G. R., y Schilling, M. A. (2015). Administración Estratégica: Teoría y casos. Un enfoque integral (11.a ed). Ciudad de México: Cengage.

Kaplan , R. S., y Norton, D. P. (2001). Como utilizar el Cuadro de Mando Integral. Barcelona: Ediciones Gestión 2000 .

Olve, N. G., Roy, J., \& Wetter, M. (2000). Implantando y gestionando el cuadro de mando integral. Barcelona: Gestión 2000.

Osterwalder, A. (2012). Generación de modelos de negocio: un manual para visionarios, revolucionarios y retadores. Barcelona: Deusto.

Porter, M. E. (2010). Ventaja Competitiva: Creación y sostenibilidad de un rendimiento superior. Madrid: Pirámide.

Robbins, S. P., y Coutler , M. (2014). Administración. México D.F: Pearson.

RPP. (18 de 06 de 2019). RPP. Obtenido de RPP:

https://rpp.pe/economia/economia/ministerio-de-economia-revisaria-la-bajaproyeccion-del-crecimiento-de-la-economia-peruana-para-este-ano-noticia1203297

Thompson, A. A., Gamble, J. E., Peteraf, M. A., y Strickland III, A. (2015). Administración Estratégica. México D.F: Mc Graw Hill. 
Wheelen, T. L., \& Hunger, J. D. (2013). Administración estratégica y política de negocios. Bogotá: Pearson. 


\section{BIBLIOGRAFÍA}

América Economía. (19 de 05 de 2019). América Economía. Recuperado de América Economía: https://www.americaeconomia.com/economiamercados/comercio/exportaciones-peruanas-de-frutas-crecieron-95-en-elprimer-trimestre-de

Banco Central de Reserva del Perú. (06 de 2019). Banco Central de Reserva del Perú. Recuperado de Banco Central de Reserva del Perú: Banco Central de Reserva del Perú

Bell, D. E., y Kindred, N. (2016). Camposol ( caso 518-S10). Recuperado de Universidad Harvard, Escuela de Negocios: https://www.harvard.edu/

Benavides Pañeda, J. (2014). Administración. México D.F: Mc Graw Hill.

Benjamín, E., y Fincowsky, F. (2009). Organización de empresas. México D.F: Mc Graw Hill.

Betancourt G., B. (2014). Análisis sectorial y competitividad. Bogotá: Primera Edición.

Camposol. (22 de 08 de 2019). Camposol. Recuperado de Camposol:

https://www.camposol.com.pe/

Castillo, N. (03 de 02 de 2019). El Comercio. Recuperado de El Comercio: https://elcomercio.pe/economia/peru/tlc-peru-estados-unidos-cumple-10-anosvigencia-sido-impacto-exportaciones-comex-mincetur-noticia-603978

Daft, R. L., y Marcic, D. (2010). Introducción a la administración. México D.F: Cengage Learning.

David, F. (1997) Conceptos de Administración Estratégica.

David, F. R. (2013). Conceptos de administración estratégica. México: Pearson.

David, F. R., y David, F. R. (2017). Conceptos de administración estratégica. Ciudad de México: Pearson. 
El Comercio. (30 de 05 de 2019). El Comercio. Recuperado de El Comercio: https://elcomercio.pe/economia/peru/ccl-nuevo-enfrentamiento-ejecutivocongreso-afectar-crecimiento-e-inversiones-noticia-nndc-640099

Gestión. (04 de 04 de 2019). Gestión. Recuperado de Gestión:

https://gestion.pe/economia/tlc-peru-china-concluye-primera-rondanegociaciones-optimizar-nndc-263319-noticia/

Gestión. (09 de 06 de 2019). Gestión. Recuperado de Gestión:

https://gestion.pe/economia/dolar-analistas-empresas-elevaron-proyeccion-tipocambio-ano-269594-noticia/

Ghemawat, P. (2007). Estrategia y el panorama empresarial. Madrid: FT Prentice Hall.

Gobierno del Perú. (9 de Abril de 2019). Plataforma digital única del estado peruano. Recuperado de Plataforma digital única del estado peruano: https://www.gob.pe/institucion/minagri/noticias/27341-ministra-fabiola-munozafirma-que-con-ampliacion-de-ley-de-promocion-agraria-se-buscara-beneficiara-pequenos-productores

Griffin, R. (2011). Administración. México D.F: Cengage Learning.

Hill, C. W., Jones, G. R., y Schilling, M. A. (2015). Administración Estratégica: Teoría y casos. Un enfoque integral (11.a ed). Ciudad de México: Cengage.

Kaplan , R. S., y Norton, D. P. (2001). Como utilizar el Cuadrode Mando Integral. Barcelona: Ediciones Gestión 2000 .

Kaplan, R. S., y Norton, D. P. (2001). Como utilizar el cuadro de mando integral. Barcelona: Gestión 2000.

Olve, N. G., Roy, J., y Wetter, M. (2000). Implantando y gestionando el cuadro de mando integral. Barcelona: Gestión 2000.

Osterwalder, A. (2012). Generación de modelos de negocio: un manual para visionarios, revolucionarios y retadores. Barcelona: Deusto.

Porter, M. E. (2010). Ventaja Competitiva: Creación y sostenibilidad de un rendimiento superior. Madrid: Pirámide.

Rankia, (2019) . Recuperado de: 
https://www.rankia.pe/blog/analisis-igbvl/2341473-empresas-mas-importantesperu-sector-agroindustrial-pesca

Robbins, S. P., y Coutler , M. (2014). Administración. México D.F: Pearson.

RPP. (18 de 06 de 2019). RPP. Recuperado de RPP:

https://rpp.pe/economia/economia/ministerio-de-economia-revisaria-la-bajaproyeccion-del-crecimiento-de-la-economia-peruana-para-este-ano-noticia1203297

Thompson (1998) Dirección y Administración Estratégicas, Conceptos, casos y lecturas.

Thompson, A. A., Gamble, J. E., Peteraf, M. A., y Strickland III, A. (2015). Administración Estratégica. México D.F: Mc Graw Hill.

Wheelen, T. L., y Hunger, J. D. (2013). Administración estratégica y política de negocios. Bogotá: Pearson. 
ANEXOS 


\section{Anexo 1: Datos Macroeconómicos}

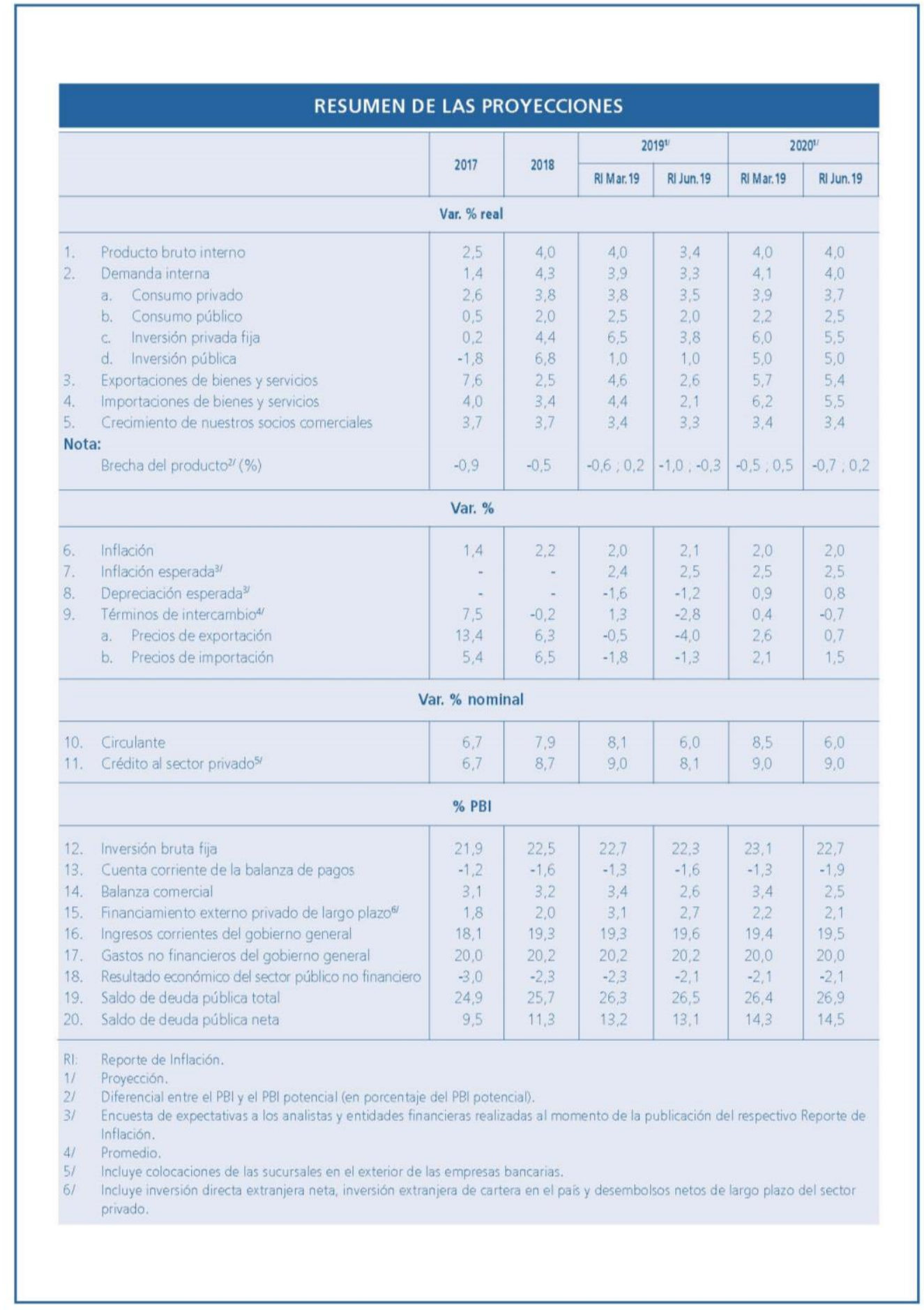

Fuente: Banco central de Reserva del Perú, 2019. 


\section{Anexo 2:Proyección de Tipo de Cambio}

\section{ENCUESTA DE EXPECTATIVAS MACROECONÓMICAS: TIPO DE CAMBIO (S/ por US\$)*}

\begin{tabular}{|c|c|c|c|c|}
\hline \multicolumn{4}{|c|}{ Encuesta realizada al: } & \\
\hline & 31 de Mar. & 30 de Abr. & 31 de May. & \\
\hline \multicolumn{5}{|c|}{ ANALISTAS ECONÓMICOS ${ }^{1 /}$} \\
\hline 2019 & 3,32 & 3,31 & 3,35 & ن \\
\hline 2020 & 3,34 & 3,35 & 3,37 & $\hat{\mathrm{U}}$ \\
\hline 2021 & 3,36 & 3,36 & 3,40 & \\
\hline \multicolumn{5}{|c|}{ SISTEMA FINANCIERO ${ }^{2 /}$} \\
\hline 2019 & 3,30 & 3,30 & 3,35 & \\
\hline 2020 & 3,32 & 3,35 & 3,35 & $=$ \\
\hline 2021 & 3,34 & 3,35 & 3,35 & \\
\hline \multicolumn{5}{|c|}{ EMPRESAS NO FINANCIERAS ${ }^{3 /}$} \\
\hline 2019 & 3,33 & 3,32 & 3,35 & \\
\hline 2020 & 3,36 & 3,37 & 3,37 & $=$ \\
\hline 2021 & 3,40 & 3,40 & 3,40 & \\
\hline \multicolumn{5}{|c|}{ 1/ 22 analistas en marzo, 21 en abril, y 21 en mayo de 2019.} \\
\hline \multicolumn{5}{|c|}{ 21 20 empresas financieras en marzo, 21 en abril, y 19 en mayo de 2019.} \\
\hline \multicolumn{5}{|c|}{ 3/ 326 empresas no financieras en marzo, 320 en abril, y 340 en mayo de 2019.} \\
\hline
\end{tabular}

Fuente: Gestión (2019). 


\section{Anexo 3: Competidores de Camposol en Perú}

\begin{tabular}{|c|c|c|}
\hline Ranking & Empresa & $\begin{array}{l}\text { Cifra de ventas } \\
2017 \text { (USS mill) }\end{array}$ \\
\hline 1 & Camposol & 369,0 \\
\hline 2 & Louis Dreyfus Perú & 363,0 \\
\hline 3 & Contilatin del Perú & 341,0 \\
\hline 4 & Palmas del Espino S.A. y SUB & 222,0 \\
\hline 5 & Cargill Americas Perú & 215,3 \\
\hline 6 & $\begin{array}{l}\text { Chimú Agropecuaria / De San } \\
\text { Fernando }\end{array}$ & 185,1 \\
\hline 7 & Sociedad Agrícola Virú & 178,9 \\
\hline 8 & Molinos \& Cía & 173,2 \\
\hline 9 & Danper & 171,0 \\
\hline 10 & $\begin{array}{l}\text { British American Tobacco del Perú } \\
\text { Holding }\end{array}$ & 151,1 \\
\hline
\end{tabular}

Fuente: Rankia (2019) 